\title{
LA PLATAFORMA CONTINENTAL MÉXICO-ESTADOS UNIDOS DE AMÉRICA. EL CASO DEL POLÍGONO OCCIDENTAL EN EL GOLFO DE MÉXICO
}

RESUMEN: Los trabajos aquí presentados son el resultado de la Mesa Redonda organizada por la Coordinación del Programa de Posgrado en Derecho y el Instituto de Investigaciones Jurídicas, la cual se llevo a cabo el 12 de agosto de 2001. El objetivo fue ofrecer una visión completa de la problemática relativa a la delimitación de la Plataforma Continental en el derecho internacional y sus implicaciones en la región del Golfo de México, con el propósito de esclarecer un tema que desde la publicación del "Tratado sobre delimitación de Plataforma Continental en la región occidental del Golfo de México más allá de las 200 millas náuticas" causó gran interés entre la comunidad científica del país. El tema fue tratado tanto desde el punto de vista técnico, como del jurídico, ambas visiones se presentan a continuación.

ABSTRACT: The works here presented are the result of the Round Table held by the Law Postgraduate Program and the Legal Research Institute, on Agust 12 2001. The objective was to picture a complete perspective of the problems related to continental shelf delimitation in international law, and its implications in the Gulf of Mexico. The aim was to establish the situation evolved since the ratification of the "Treaty of Continental Shelf Delimitation in the western section of the Gulf of Mexico beyond 200 nautical miles", which generates remarkable interest in the among the members of the scientific community. The subject was dealt with from both the technical and legal perspectives.

RESUMÉ: Les travaux présentés sont le résultat d'une Table Ronde qui s'est tenue le 12 août 2001 et a été organisée par la Coordination du Programme de Troisième Cycle en Droit et l'Institut de Recherches Juridiques. Le but était d'offrir une vision complète de la problématique relative à la délimitation de la plate-forme continentale en droit international et ses implications dans la région du Golfe du Mexique, à fin d'éclaircir un sujet, qui depuis la publication du "Traité sur la délimitation de la Plate-forme Continentale dans la région du Golfe du Mexique, au-delà de 200 milles nautiques", a soulevé un grand intérêt dans la communauté scientifique du pays. Tout au long de l'article, le sujet a été abordé aussi bien d'un point de vue technique que juridique. 


\title{
TRATADO SOBRE DELIMITACIÓN DE LA PLATAFORMA CONTINENTAL ENTRE MÉXICO Y LOS ESTADOS UNIDOS DE AMÉRICA DEL 9 DE JUNIO DE 2000
}

\section{Alonso GóMEZ-RoBLEDO VERDUZCO*}

\begin{abstract}
SUMARIO: I. Introducción. II. Denominador común a la delimitación marítima. III. Definición de la Plataforma Continental. IV. La delimitación en la jurisprudencia internacional y práctica estatales. V. Delimitación de la Plataforma Continental entre México y Estados Unidos de América. VI. Conclusión.
\end{abstract}

\section{INTRODUCCIÓN}

Los problemas concernientes a las delimitaciones de zonas marítimas, desde un punto de vista meramente técnico, se puede decir que eran problemas realmente sencillos de resolver en la mayor parte de los casos.

La anchura de las aguas territoriales no eran más que de unas cuantas millas; las líneas de base que servían a su medición seguían generalmente la configuración de las costas.

Por las delimitaciones en la actualidad conciernen grandes distancias que tienen ya no únicamente por objeto una frontera de 3 o 12 millas náuticas, sino de grandes extensiones cubiertas por las zonas económicas exclusivas y por las plataformas continentales o insulares.

Todas y cada una de las negociaciones, ya sean bilaterales o multilaterales, presentan un conjunto único de problemas, entre los que se encuentran: las múltiples diferencias en la configuración de la línea de la costa, la presencia de islas, rocas o elevaciones que emergen en alta mar, la morfología del lecho marino, la distribución de recursos vivos y no vivos, etcétera. 
Las reglas generales sobre delimitación entre dos o más Estados están todavía originándose a través de un proceso gradual de formación, debido principalmente a la obra de la jurisprudencia internacional. Aun cuando son cada día más numerosos los casos sometidos al arbitraje y a la judicatura internacional, sin embargo, como ha dicho Tullo Scovazzi, no parece que se haya ya formado un corpus tan consistente como para consentir a la individualización de reglas generales suficientemente precisas y consolidadas en la práctica internacional.

Por otro lado, es indiscutible que el derecho de la delimitación de la Plataforma Continental ha sido considerado como el prototipo del derecho de toda delimitación marítima, aunque no resulte evidente a primera vista que la delimitación del mar territorial, la plataforma y la zona económica exclusiva deban obedecer a los mismos principios y reglas de derecho, ya que por su mismo objeto se aplican a jurisdicciones de naturaleza jurídica diversa.

Desde 1969, la corte ha considerado que la no aplicabilidad de las disposiciones convencionales de 1958 no equivalía a una ausencia de reglas jurídicas, y desde entonces tanto sentencias judiciales como fallos arbitrales no han dejado de insistir en la obligación impuesta al juez internacional para dirimir las controversias sobre la base del derecho, no confiriéndole así la facultad de decidir, en forma alguna, un litigio ex aequo et bono.

Poco a poco, y a través de la sucesión de casos sometidos a la jurisprudencia internacional, se puede sostener que el juez no puede ya cumplir con su misión, con sólo declarar sencillamente que un trazado de delimitación es el adecuado porque él, simple y llanamente, lo considera equitativo. Es necesario además que el juez internacional sea capaz de justificar la línea de delimitación a la luz de principios equitativos de contenido normativo.

Por lo anterior, uno de los graves problemas que presenta el derecho de la delimitación marítima es encontrar ese equilibrio necesario entre un cierto grado de generalidad que debe revestir toda norma jurídica, pero en conjunción estrecha con el criterio de equidad, teniendo muy en cuenta no llevar la equidad hasta posiciones ilógicas de una individualización extrema de la regla misma de derecho, la que obviamente, si esto último fuere el caso, perdería toda connotación de regla normativa. 


\section{DENOMINADOR COMÚN A LA DELIMITACIÓN MARÍTIMA}

El denominador común aplicable a toda delimitación marítima - -y sobre la cual no parece haber discusión mayor en la jurisprudencia internacional- es aquél según el cual la delimitación debe ser realizada mediante utilización de métodos prácticos y por aplicación de "principios equitativos" que sean aptos para asegurar un resultado equitativo, habida cuenta de la configuración geográfica de la región y de otras "circunstancias pertinentes" al caso concreto. ${ }^{1}$

Así, en el Caso de la Delimitación de la Frontera Marítima en la Región del Golfo de Maine, la Corte Internacional de Justicia sostuvo que ninguna delimitación marítima entre Estados cuyas costas sean adyacentes o se sitúen frente a frente, no podía efectuarse de manera unilateral por uno u otro de los Estados. Esta delimitación debe realizarse mediante un acuerdo, resultado de una negociación llevada a cabo de buena fe y con la intención real (genuine intention) de poder llegar a un resultado positivo.

En caso de que un acuerdo no pueda llegar a celebrarse, la delimitación debe ser efectuada recurriendo a una tercera instancia dotada de la competencia necesaria a tal fin: "Dans le premier cas, comme dans le second, la délimitation doit être réalisée por l'application des critères équitables et par l'utilisation de méthodes pratiques aptes à assurer, compte tenu de la configuration geographique de la région et des autres circonstances pertinentes de l'espèce, un résultat équitable". ${ }^{2}$

1 Véase Gómez-Robledo, Alonso, "Métodos de delimitación en derecho internacional del mar y problema de las islas", en varios autores, Los espacios marítimos y su delimitación, México, Secretaría de Energía, 1999, pp. 135-218.

2 Véase CIJ, "Arrêt du 12 octobre 1984 rendu por la Chambre constituée par Ordonnance de la Cour du 20 Janvier 1982”, Recueil des Arrêts, Avis Consultatifs et Ordannances, pp. 299 y 300, párrafo 112. Los casos de la Plataforma Continental en Mar del Norte, siguen siendo de un valor excepcional para la comprensión de la naturaleza jurídica de la Plataforma Continental y su delimitación. En su sentencia del 20 de febrero de 1969, la corte sostuvo que la delimitación debía operarse vía de acuerdo, conforme a principios equitativos y habida cuenta de todas las circunstancias pertinentes, para atribuir, en toda la medida de lo posible, a cada parte la totalidad de las zonas de la Plataforma Continental que constituyen la prolongación natural de su territorio bajo el mar, y en forma tal que no vaya a existir un solapamiento sobre la prolongación natural del territorio de un tercero; véase "Affaires du Plateau Continental de la Mer du Nord" (RFA/Denemark; RFA/Pays-Bas), CIJ, Recueil des Arrêts, Avis Consultatifs et Ordonnances, 1969, p. 53, párrafo 101. Véase el ilustrativo análisis sobre el método de delimitación fundado sobre la "equidistancia" del juez mexicano Padilla Nervo, Luis, “Separate Opinion of Judge Padilla Nervo", op. cit., pp. 86-99. 
Debemos dejar bien asentado que los "principios equitativos", también llamados en ocasiones criterios o factores equitativos (Arbitraje; Guinea vs. Guinea Bissau 1982) no son mera retórica, sino verdaderas máximas legales, que junto con las denominadas "circunstancias pertinentes" integran una dualidad indisociable.

Es evidente que los "principios equitativos" — como lo ha puesto de manifiesto la jurisprudencia-, susceptibles de ser tomados en consideración para una delimitación marítima internacional, no pueden ser objeto de una definición sistemática y a priori, en razón de su muy variable adaptabilidad a situaciones concretas mucho muy diversas.

En el Caso de la Delimitación de la Frontera Marítima en la Región del Golfo de Maine, entre Canadá y Estados Unidos de América, la Corte Internacional de Justicia sostuvo que podrían recordarse como "criterios equitativos", el expresado en la fórmula clásica de que la tierra domina el mar; el principio de no solapamiento entre áreas de Plataforma Continental; el relativo a evitar, en lo posible, un efecto de amputación de la proyección marítima de la costa de uno de los Estados concernidos. ${ }^{3}$

En un esfuerzo de mayor esclarecimiento, la Corte Internacional de Justicia, en el Caso de la Plataforma Continental entre Libia y Malta de 1985, va a precisar que el carácter normativo de los "principios equitativos" aplicados en el marco del derecho internacional general, son importantes, en virtud de que dichos principios gobiernan no solamente la delimitación por vía judicial o por vía arbitral, sino también y primordialmente, porque imponen la obligación a las partes de buscar, en primer lugar, una delimitación por vía de acuerdo, lo que implica igualmente buscar un resultado equitativo.

Acto seguido, la corte va a enunciar, a título ejemplificativo, varios principios, considerados como "principios equitativos" en la jurisprudencia y susceptibles además de una aplicación general:

a) El principio según el cual, no sería en ningún momento cuestión de rehacer completamente la geografía ni de rectificar las desigualdades de la naturaleza.

b) El principio vecino de no solapamiento de una parte sobre la prolongación natural de la otra; y que no es sino la expresión negativa

3 Véase CIJ, Recueil des Arrêts, Avis Consultatifs et Ordonnances, 1984, pp. 312 y 313, párrafo 157 . 
de la regla positiva, según la cual, el Estado costero goza de derechos soberanos sobre la plataforma que bordea sus costas en toda la extensión que autoriza el derecho internacional, de conformidad con las circunstancias pertinentes.

c) El respeto debido a todas y cada una de dichas circunstancias pertinentes o relevantes.

d) El principio según el cual, aún y cuando todos los Estados son iguales entre sí conforme a derecho y puedan pretender un tratamiento igual, la equidad no implica necesariamente la igualdad (equity does not necessarily imply equality), ${ }^{4} \mathrm{ni}$ apunta tampoco, a convertir en igual, lo que la naturaleza ha hecho desigual.

e) El principio según el cual en ningún momento se estaría tratando de una especie de justicia distributiva. ${ }^{5}$

Teóricamente, "principios equitativos" y "circunstancias pertinentes" se sitúan en planos diferentes, como bien lo ha señalado el profesor Prosper Weil. El concepto de circunstancias pertinentes, hace referencia a hechos brutos, tales como la concavidad de una costa, la presencia de una isla, la diferencia entre la extensión de las fachadas costeras.

En cambio, el concepto de principios equitativos implica un juicio sobre dichos elementos de hecho, y una cierta visión en cuanto al objetivo que se persigue en una delimitación.

Sin embargo, en la realidad, como sostiene la doctrina más seria, circunstancias pertinentes y principios equitativos integran, como dijimos antes, una dualidad indisociable. Sin el auxilio de los principios equitativos, las circunstancias pertinentes estarían imposibilitadas para generar una apreciación de equidad.

En realidad pues, los principios equitativos, como señala P. Weil, no toman cuerpo que por referencia a las circunstancias pertinentes del caso, y las circunstancias pertinentes del caso concreto, no devienen operacionales más que con el auxilio y en el contexto de los principios equitativos. $^{6}$

\section{ICJ, Reports, 1969, p. 49, párrafo 91}

5 Véase CIJ, “Affaire du Plateau Continental, Jamahiriya Árabe Lybyenne/Malte”, Arrêt du 3 juin 1985, Recueil des Arrêts, Avis Consultatifs et Ordonnances, pp. 39 y 40, párrafo 46.

6 Véase (1) Weil, Prosper, "A propos du droit coutumier en matière de delimitation maritime", en varios autores, Études en l'Honneur de Roberto Ago: Le Droit International à l'heure de sa codification, Milán, Giuffrè, 1987, vol. II, pp. 535-552. (2) Id., "L'équité dans la jurisprudence de la Cour Internationale de Justice", en varios autores, Essays in Honour of Sir Robert Jennings: Fifty years of the 


\section{DEFINICIÓN DE LA PLATAFORMA CONTINENTAL}

La Convención de las Naciones Unidas sobre el Derecho del Mar, firmada en Montego Bay, Jamaica, el 10 de diciembre de 1982, y en vigor a partir del 16 de noviembre de 1994, es decir 12 meses después de que se depositara el sexagésimo instrumento de ratificación (Guyana), consagra en su artículo 76 lo siguiente:

La Plataforma Continental de un Estado ribereño comprende el lecho y el subsuelo de las áreas submarinas que se extienden más allá de su mar territorial y a todo lo largo de la prolongación natural de su territorio hasta el borde exterior del margen continental, o bien hasta una distancia de 200 millas marinas contadas desde las líneas de base a partir de las cuales se mide la anchura del mar territorial, en los casos en que el borde exterior del margen continental no llegue a esa distancia (artículo 76, párrafo 1).

En la cuasi totalidad de las regiones del mundo, el fondo del mar va descendiendo en forma gradual a partir de la costa, prolongándose en una gran extensión, hasta antes de que se interrumpa por un muy brusco descenso, a través de una fuerte pendiente que conduce hacia las simas oceánicas, o fondos abisales (véase dibujo en la página siguiente).

Esta zona del fondo marino que es una especie de cornisa que bordea en forma más o menos acentuada las islas y los continentes, ha sido denominada como Plataforma Continental o litoral, y planicie insular.

La extensión de la Plataforma Continental es muy variable, ya que en algunas regiones tiene una extensión relativamente insignificante (Costa occidental de América del Sur), en tanto que en otras regiones alcanza una extensión de 800 o más millas (Mar de Bering).

Los derechos del Estado ribereño sobre su Plataforma Continental son derechos soberanos, exclusivos e incondicionales, en el sentido siguiente: si el Estado no ocupa o explota su plataforma, ningún otro Estado puede emprender dicha explotación, sin su expreso consentimiento.

International Court of Justice, Cambridge University Press, 1996, pp. 121-144. El principio de "no solapamiento", por ejemplo, no reviste una significación precisa más que en relación con las circunstancias geográficas concretas que conducen a la línea de la equidistancia, a aproximarse, en mayor o menor grado, a las costas de cada una de las partes. Véase Jiménez de Aréchaga, Eduardo, "The conception of equity on maritime delimitation", en varios autores, Études en l'Honneur de Roberto Ago..., cit., en esta misma cita, vol. II, pp. 228-239. 


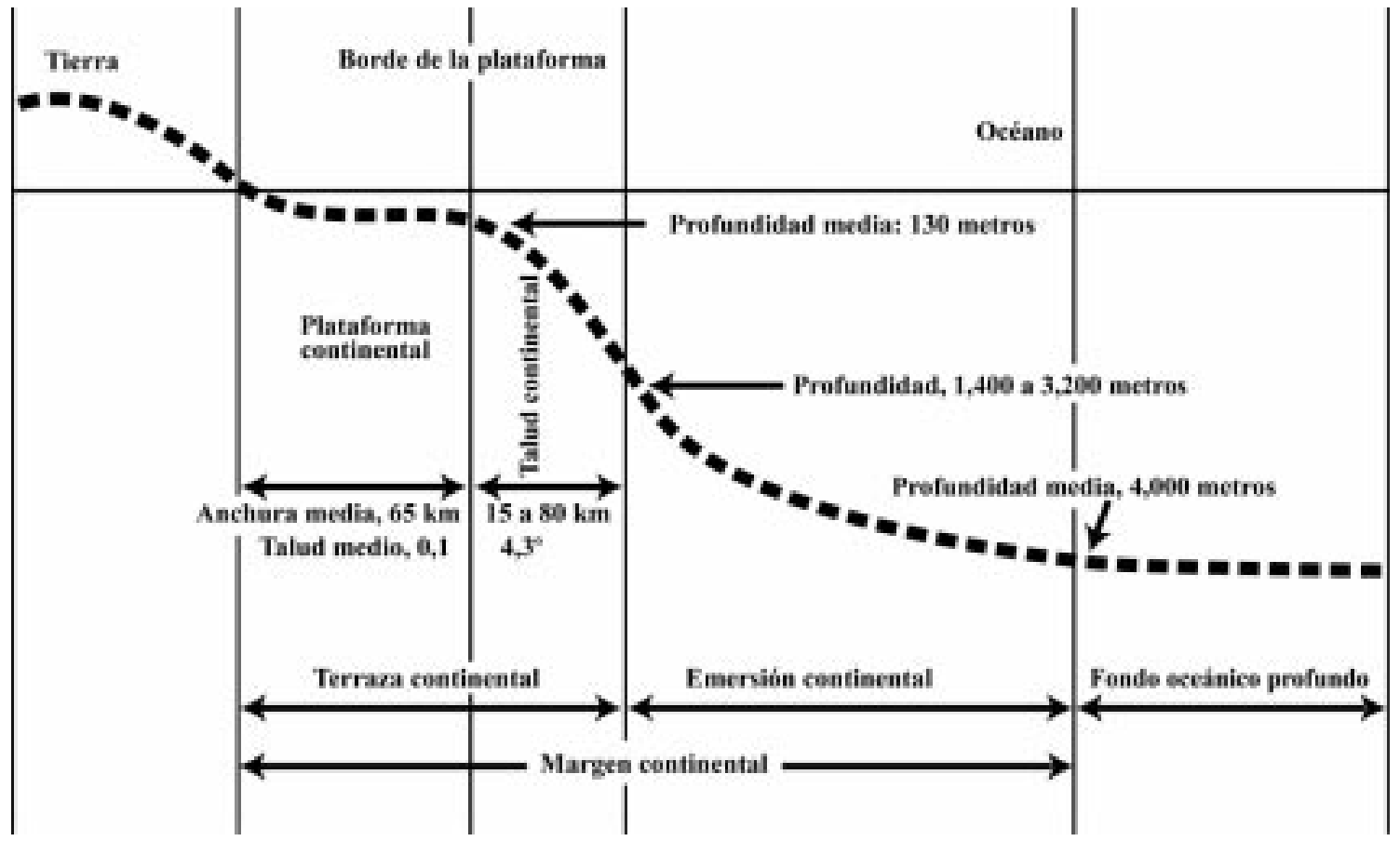

FUENTE: Definición de la Plataforma Continental, División de Asuntos Oceánicos y del Derecho del Mar, Nueva York, Naciones Unidas, 1994. 
La Corte Internacional de Justicia, en su famosa sentencia de 1969 en los casos del Mar del Norte, hablará de derechos del Estado ribereño, generados ipso facto y ab initio. ${ }^{7}$

Uno de los grandes problemas en la práctica estatal es precisamente aquél en donde el Estado ribereño cuenta con una Plataforma Continental que rebasa las 200 millas marinas, ya que la Convención de Montego Bay consagra, en estos casos, disposiciones complejas y de un gran tecnicismo.

De acuerdo con la Convención de 1982, dondequiera que el margen se extienda más allá de las 200 millas marinas, el Estado ribereño establecerá el borde exterior del margen continental mediante una línea trazada en relación con los puntos fijos más alejados en cada uno de los cuales el espesor de rocas sedimentarias sea por lo menos el $1 \%$ de la distancia más corta entre este punto y el pie del talud continental. O bien una línea trazada, en relación con puntos fijos situados a no más de 60 millas marinas del pie del talud continental.

Los puntos fijos que constituyen la línea del límite exterior de la Plataforma Continental en el lecho del mar "deberán estar situados a una distancia que no exceda de 350 millas marinas contadas desde las líneas de base a partir de las cuales se mide la anchura del mar territorial, o de 100 millas marinas contadas desde la isóbata de 2.500 metros, que es una línea que une profundidades de 2.500 metros" (artículo 76, párrafo 4, inciso a); párrafo 5 y párrafo 7 de la $\mathrm{CMB}$ ).

Es cierto pues que las disposiciones de la Convención de 1982 llegan a la adopción de una fórmula híbrida y compleja, que bien puede ser percibida como una verdadera amalgama de todos los principales tipos de criterios que habían sido propuestos. Pero esto no es más que la consecuencia de las ásperas negociaciones a las cuales dieron lugar la técnica de la negociación en "paquete" y la necesidad de lograr a todo precio un consenso, so pena de poner en peligro la Convención en su totalidad. ${ }^{8}$

7 Véase Gómez-Robledo V., Alonso, El nuevo derecho del mar: guía introductiva a la Convención de Montego Bay, México, Miguel Ángel Porrúa, 1986, pp. 71-78.

8 Véase Castañeda, Jorge, "La Conférence des Nations Unies sur le Droit de la Mer et l'Avenir de la Diplomatie Multilaterale", en varios autores, Etudes en l'Honneur de Roberto Ago, cit., nota 6, pp. 74-85. El presidente de la delegación de México a la III Confemar, el jurista don Jorge Castañeda y el embajador de Noruega H. Vindennes, reunieron un conjunto de delegaciones representativas de todos los puntos de vista a debatir sobre el difícil problema relativo a la naturaleza jurídica de la ZEE y del arreglo de diferendos aplicables a la pesca y a la investigación científica. Este grupo tuvo una influencia decisiva en los trabajos de la tercera comisión y de la plenaria oficiosa, así como sobre las de la segunda comisión. 


\section{LA DELIMITACIÓN EN LA JURISPRUDENCIA INTERNACIONAL Y PRÁCTICA ESTATALES}

\section{En el Arbitraje de 1975 sobre la delimitación de la Plataforma Continental en Mar d'Iroise}

Las partes (Inglaterra y Francia) solicitaban al tribunal decidir conforme al derecho internacional aplicable a la materia, la cuestión siguiente: ¿Cuál debería ser el trazado de la línea o líneas, delimitando las zonas de la Plataforma Continental que correspondían respectivamente al Reino Unido, así como las islas anglo-normandas y de la república francesa, al oeste de la longitud 30 minutos oeste al Meridiano de Greenwich y hasta la isóbata de 1000 metros?

La trascendencia de este arbitraje era indiscutible, pues como sostuvo el profesor D. W. Bowett representaba la primera operación de delimitación de plataformas continentales realizada por un tribunal internacional. En los casos de la Plataforma Continental en Mar del Norte de 1969, a la corte se le había solicitado únicamente, el determinar los principios y reglas aplicables a la delimitación.

En este Arbitraje, el tribunal se pronunció sin titubeos por la aplicación de la regla "equidistancia-circunstancias especiales", como parte del derecho internacional consuetudinario, y esto queda plasmado con claridad tanto en la delimitación efectuada en el área del Canal, como en la del Atlántico. ${ }^{9}$

\section{En el Caso de la delimitación de la Plataforma Continental} entre Túnez y Libia (1982)

Las partes solicitan a la Corte Internacional de Justicia que en la operación de delimitación tomara en cuenta los principios equitativos, las circunstancias propias a la región que fueron pertinentes, y las nuevas tendencias sobre derecho del mar, tal y como se desprendían de la III Confemar.

9 Véase "Affaire de la Délimitation du Plateau Continental entre Royaune-Uni de Grande Bretagne et d'Irlande du Nord' et République Française”, Recueil des Sentences Arbitrales, vol. XVIII, Nations Unies, pp. 130, 270. El análisis crítico de este arbitraje puede consultarse en Gómez-Robledo V., Alonso, Jurisprudencia internacional en materia de delimitación marítima, México, UNAM-IIJ, 1989, pp. 65-93. 
El pasaje siguiente del caso es, sin duda, de una gran importancia para la jurisprudencia de la corte:

La aplicación de principios equitativos debe lograr un resultado equitativo. Esta manera de expresarse, aún y cuando es generalmente utilizada, no puede ser completamente satisfactoria, ya que el adjetivo equitativo, está calificando a la vez el resultado que se tiende a lograr, y los medios por los cuales se pretende llegar a dicho fin. Sin embargo, es el resultado lo que es importante: los principios están subordinados al objetivo que se pretende lograr... Todos los principios no pueden ser en sí mismos equitativos; es la equidad de la solución, la que les va a conferir dicha calidad... ${ }^{10}$

En opinión de la corte, el cambio radical de orientación de la costa tunecina parecería modificar hasta cierto grado, pero no completamente, la relación existente entre Libia y Túnez, que siendo Estados limítrofes en un principio, tienden a convertirse en Estados con costas situadas frente a frente.

Se llega así a una situación en la cual el trazado de una línea de equidistancia se convierte en un factor que pesa más de lo que normalmente lo haría, respecto a la apreciación global de las consideraciones de equidad.

En su fallo del 24 de febrero de 1982, adoptado por 10 votos a favor y cuatro en contra, la Corte Internacional de Justicia va a reiterar que la delimitación debería efectuarse de conformidad con principios equitativos y circunstancias pertinentes, y que la región que debería tomarse en consideración para fines de delimitación consistía en una sola Plataforma Continental, prolongación natural del territorio terrestre de las dos partes. ${ }^{11}$

\section{Caso de la delimitación de la frontera marítima en la región del Golfo de Maine}

El gobierno canadiense y el gobierno norteamericano acordaron por vía de compromiso someter su controversia de delimitación sobre Plataforma Continental y zona de pesca, conjuntamente y mediante el trazado de una sola línea, ante una sala de la Corte Internacional de Justicia, pun-

10 Véase "Affaire du Plateau Continental-Tunisie/Jamahiriya Árabe Libyenne", Arrêt du 24 février 1982, Recueil des Arrêts, Avis Consultatifs et Ordonnances, p. 59, párrafo 70. La sentencia de 1985 decidió sobre la demanda, presentada por Túnez, de revisión e interpretación de la primera sentencia. CIJ, Recueil des Arrêts..., 1985, p. 192.

11 Véase ibidem, p. 92, párrafo 133. Los siguientes jueces votaron en contra de la sentencia de la corte: André Gros, Shigeru Oda, Forester y el juez ad hoc Jens Evensen. Para un análisis crítico del caso, consúltese: Gómez-Robledo V., Alonso, Jurisprudencia internacional..., cit., nota 9, pp. 95-128. 
to intermedio entre la jurisdicción obligatoria y el arbitraje. Este mecanismo parece contribuir a una mayor confianza por parte de los Estados en el sometimiento de sus diferendos a la judicatura internacional.

La sala de la corte va a proceder a dividir el área a limitar en tres sectores. En el primero de ellos, la sala utiliza un método geométrico, basado en el respeto a la situación geográfica de las costas, y que no es, en realidad, sino la utilización de una línea de equidistancia en forma simplificada, ya que cada punto de la bisectriz se halla a la misma distancia de ambas rectas del punto del ángulo elegido.

En lo concerniente al segundo segmento, la sala procedería por dos etapas. Provisionalmente fijaría una delimitación de base, y después tomaría en consideración los correctivos necesarios en vistas a las "circunstancias especiales" del caso concreto. Aquí, e incluso más que en el primer segmento, y aunque la sala de la corte no lo diga, se hace uso del método de la equidistancia, exactamente en el sector en donde las costas canadiense y norteamericana llegan a situarse frente a frente.

En cuanto al tercer sector de la línea de delimitación, y habida cuenta que el trazado de la línea de delimitación debía efectuarse en pleno océano, la sala consideró, una vez más, que el único método práctico que podría ser tomado en consideración era un "método geométrico", y que en el caso concreto consistía en el trazado de una perpendicular con relación a la línea del cierre del Golfo de Maine. ${ }^{12}$

\section{Caso de la Plataforma Continental entre la República de Malta} y la República Árabe de Libia de 1985

La Corte Internacional de Justicia, tras analizar los principios y circunstancias pertinentes al caso, realiza un trazado previo, mediante una línea media entre las costas de Malta y de Libia, para luego corregirla en

12 Véase CIJ, "Affaire de la delimitation de la frontiére maritime dans le région du Golfe du Maine”, Arrêt du 12 octobre 1984, Recueil des Arrêts, Avis Consultatifs et Ordonnances, Canada/Estats-Unis d'Amérique, 1984. En el tercer sector se vuelve a utilizar el método de la equidistancia. Basta y sobra el ver con atención los mapas anexos a la sentencia de la sala de la corte de 1984, para comprobar cómo la línea trazada en este tercer segmento es la continuación de la línea establecida para el segundo segmento. Como se ha hecho notar por la doctrina, si la operación de la delimitación comienza necesariamente por la equidistancia, esto no implica el que necesariamente deba terminarse por el mismo método. Una vez trazada dicha línea como un primer paso para la delimitación, llega el momento en donde se deberá establecer si el método de la equidistancia es conveniente ya que es un medio para efectuar una delimitación, "justa" y "equitativa", Sentencia de 1977 sobre el Mar d'Iroise, párrafo 242. Para un análisis crítico del Caso del Golfo de Maine, consúltese: Gómez-Robledo V., Alonso, Jurisprudencia internacional..., cit., nota 9, pp. 131-172. 
función de las circunstancias que ha considerado como siendo relevantes, en especial la longitud de las costas, la distancia que las separa y la situación de Malta en el contexto del Mediterráneo. ${ }^{13}$

\section{Caso de la Delimitación Marítima en la Región situada entre Groenlan- dia y Jan Mayen entre Dinamarca y Noruega (1993)}

La Corte Internacional de Justicia concluiría que la línea de equidistancia trazada a título provisional, y empleada como punto de partida para la delimitación de la Plataforma Continental y de las zonas de pesca, debía de ser corregida o desplazada en virtud de la disparidad de la longitud de los litorales de los Estados en cuestión. ${ }^{14}$

\section{La práctica de los Estados en materia de delimitación marítima ratifica gran parte de la jurisprudencia internacional}

Así en el Acuerdo celebrado en Roma el 8 de enero de 1968, entre Italia y Yugoslavia, el método de la equidistancia caracteriza gran parte de la línea de delimitación de la Plataforma Continental. Un efecto reducido se atribuyó a cuatro islas situadas en la parte central del Adriático. ${ }^{15}$

En el Acuerdo de Delimitación de la Plataforma Continental entre Grecia e Italia, celebrado en Atenas, el 24 de mayo de 1977 se escogió el método de la equidistancia, aunque con algunos ajustes. Estas correcciones se refieren principalmente a las islas griegas de Fanos (a las que se les atribuyó un efecto similar a 3/4) y Strofades, a la que se le atribuyó un semiefecto. ${ }^{16}$

En el Acuerdo de Delimitación de la Plataforma Continental celebrado entre Italia y España el 10 de febrero de 1974, en la ciudad de Madrid, y en vigor a partir del 16 de febrero de 1978, de igual forma que en los casos anteriores se estipuló expresamente que la línea de delimitación se

13 Véase CIJ, Arrêt du 3 juin 1985, Recueil des Arrêts..., cit., nota 5, pp. 1-187. Véase GómezRobledo, Alonso, Jurisprudencia internacional..., cit., nota 8, pp. 175-204.

14 Véase CIJ, "Affaire de la délimitation maritime dans la région située entre le Groeland et Jan Mayen”, Arrêt du 14 juin, Recueil des Arrêts, Avis Consultatifs et Ordonnances (Danemark c. Norvège), 1993. En particular, véanse pp. 77-82, párrafos 87-94.

15 Véase texto del Acuerdo entre Italia y Yugoslavia del 8 de enero de 1968, vigente desde el 21 de enero de 1970, en Conforti, Benedeto y Francalanci, Gianapiero, Atlante dei Confini Sottomari$n i$, Milán, Dott. A. Giuffrè Editore, 1979, pp. 85-87.

16 Véase texto del Acuerdo entre Grecia e Italia del 24 de mayo de 1977, ibidem, pp. 89-91. 
fijaría aplicando el método de la equidistancia desde las líneas de base respectivas (artículo 10.).

Aquí la línea de delimitación se detiene antes del tocar los puntos equidistantes entre Francia-Italia-España y Argelia-Italia-España. ${ }^{17}$

Después de interminables y laboriosas negociaciones en el seno de la III Confemar, se logró al final consagrar la fórmula de la delimitación de la Plataforma Continental en su artículo 83, con su equivalente para la delimitación en la zona económica exclusiva en su artículo 74: "La delimitación de la Plataforma Continental entre Estados con costas adyacentes o situadas frente a frente, se efectuará por acuerdo entre ellos sobre la base del derecho internacional, a que se hace referencia en el artículo 38 del Estatuto de la Corte Internacional de Justicia, a fin de llegar a una solución equitativa" (art. 83, párrafo 10.).

Si bien la anterior formulación no es muy feliz desde el punto de vista jurídico, sin embargo tiene una ventaja política incontrovertible, ya que abrió las puertas para un acuerdo entre posturas radicales, y permitió así la adopción del conjunto del texto de la Convención de Montego Bay de 1982.

El acento está puesto sobre el resultado y en principio puede aplicarse cualquier método de delimitación. A diferencia pues de las Convenciones de Ginebra de 1958 sobre Derecho del Mar, en el régimen actual no existen reglas específicas ni menos obligatorias para la delimitación entre los Estados.

Ahora bien, la jurisprudencia internacional y la práctica estatal nos demuestra - como ya veíamos-, que la mayoría de los acuerdos de delimitación toman como criterio-base, como punto de inicio, una línea trazada según el método de la equidistancia, para luego proceder a hacerle los ajustes necesarios y correcciones pertinentes, en función de circunstancias especiales, relevantes o particulares: configuración de las costas, anchura de la fachada, longitud entre las mismas, presencia de islas, etcétera. ${ }^{18}$

17 Véase texto del Acuerdo de Delimitación entre España e Italia, ibidem, pp. 75-77.

18 En varias ocasiones, los Estados utilizan la terminología de la "línea media" para delimitaciones entre Estados cuyas costas se sitúan frente a frente, y de la "línea de equidistancia" para Estados con costas adyacentes. Pero en los dos casos se trata de líneas trazadas según el método de la equidistancia, método que produce, como dice la corte en su sentencia del 20 de febrero de 1969, una línea que atribuye a cada una de las partes interesadas, todas las porciones de la Plataforma Continental más próximas de un punto de su costa, que de cualquier otro punto situado sobre la costa de la otra parte, véase Caflisch, Lucius, "Les zones maritimes sous juridiction nationale, leurs limites et leur déli- 


\section{DELIMITACIÓN DE LA PLATAFORMA CONTINENTAL ENTRE MÉXICO Y ESTADOS UNIDOS DE AMÉRICA}

El gobierno de Estados Unidos Mexicanos y el gobierno de Estados Unidos de América celebraron el 9 de junio de dos mil un Tratado sobre la Delimitación de la Plataforma Continental en la Región Occidental del Golfo de México más allá de las 200 millas náuticas, habiendo sido firmado en la ciudad de Washington, D. C., el 9 de junio de 2000, y siendo vigente a partir del cambio de los instrumentos de ratificación el 17 de enero de 2001.19

Los límites marítimos entre las partes se determinaron sobre la base del método de la "Equidistancia", para una distancia entre doce y doscientas millas náuticas mar adentro, contadas desde las líneas de base a partir de las cuales se mide la anchura del mar territorial en el Golfo de México y el Océano Pacífico, conforme al Tratado sobre Límites Marítimos entre México y Estados Unidos de América, suscrito el 4 de mayo de 1978.

De igual manera, los límites marítimos entre las partes se determinaron sobre la base de la línea de la "Equidistancia" para una distancia de 12 millas náuticas mar adentro, contadas desde las líneas de base a partir de las cuales se mide la anchura del Mar Territorial, conforme al Tratado para Resolver las Diferencias Fronterizas Pendientes y para Mantener los Ríos Bravo y Colorado, como la Frontera Internacional entre México y Estados Unidos de América, suscrito el 23 de noviembre de 1970.

En este tratado del 9 de junio de dos mil, las partes establecieron, conforme al derecho internacional, el límite de la Plataforma Continental entre México y Estados Unidos de América, en la región occidental del Golfo de México, más allá de las 200 millas náuticas contadas desde las líneas de base a partir de las cuales se mide la anchura del Mar Territorial.

Este tratado era tanto más importante, si se tomaba en cuenta la posibilidad — por no decir la certeza — de que podrían existir sustanciales yacimientos de petróleo o de gas natural que se extendían a través del límite de la Plataforma Continental, y que en tales circunstancias, era necesaria

mitation", en Bardonnet, D. y Virally, M., Le nouveau droit international de la mer, París, Editions A. Pédone, 1983, pp. 34-116.

19 Véase Decreto promulgatorio de tratado, Diario Oficial de la Federación, jueves 22 de marzo de 2001. 
la cooperación y las consultas periódicas con el fin de proteger los respectivos intereses entre las partes.

México y Estados Unidos de América son parte en la Convención de Ginebra de 1958 sobre Plataforma Continental, y la misma entiende por tal el lecho del mar y subsuelo de las zonas submarinas adyacentes a las costas, pero situadas fuera de la zona de mar territorial hasta una profundidad de 200 metros, o más allá de este límite, hasta donde la profundidad de las aguas suprayacentes permita la explotación de los recursos naturales de la plataforma.

En la Convención sobre Derecho del Mar de 1982, de la cual México es parte, y respecto a la cual Estados Unidos de América ha aceptado que en este apartado la Convención de 1982 refleja el derecho internacional consuetudinario, la definición consagrada prevé una mejor definición científica de la Plataforma Continental, como tuvimos oportunidad de examinarlo anteriormente.

No hay que olvidar que con respecto a las áreas más allá de las 200 millas náuticas, contadas desde las líneas de base, tanto la Convención de Ginebra de 1958 como la Convención de Montego Bay de 1982 consagran una serie de criterios precisos para que la Plataforma Continental pueda ser calificada como tal (véase supra).

Durante las negociaciones del tratado, tanto México como Estados Unidos de América acordaron que tanto el suelo como el subsuelo de las áreas submarinas más allá del límite de las 200 millas náuticas de la Zona Económica Exclusiva en la región occidental del Golfo de México, reunían los requisitos exigidos por ambas convenciones.

En el artículo I del tratado se describe el "límite" de la Plataforma Continental entre México y Estados Unidos de América en la región occidental del Golfo de México más allá de las 200 millas náuticas, siendo determinado este límite (boundary) mediante líneas geodésicas, que conectan con un listado de 16 coordenadas como puntos terminales (véase diagrama en la siguiente página).

De acuerdo con la metodología utilizada en previos tratados de delimitación marítima entre los dos países, la línea actual representa una "línea equidistante" trazada desde las respectivas líneas de base de México y Estados Unidos de América, incluyendo las líneas de base de las islas.

Para la determinación del límite establecido, se utilizaron las bases geodésicas y de cálculo del Datum de Norteamérica de 1983, y el Marco 


\section{DIAGRAMA DELARTICULO 76}

El límite exterior de la plataforma continental no puede extenderse más allá de

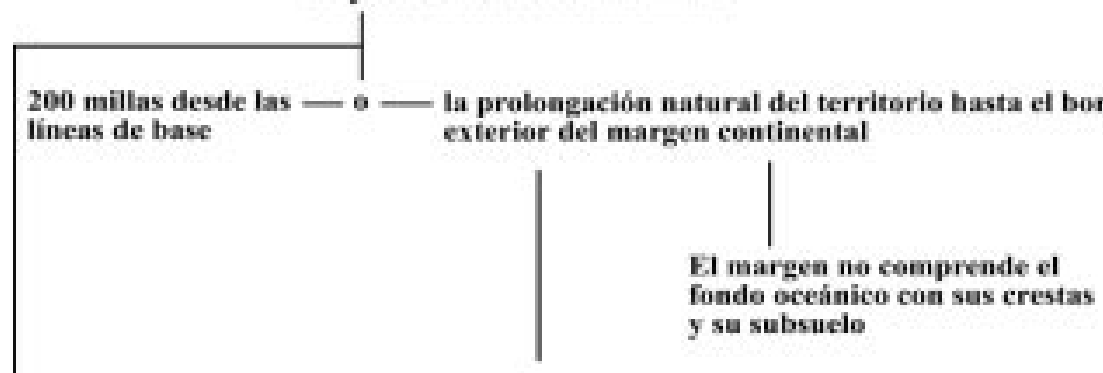

El margen comprende plataforma, taled y emersión continental

El Estado ribereño puede fijar el limite exterior de su margen continental mediante lineas rectas de hasta 60 millas de longitud que cenecten puntos ubicados

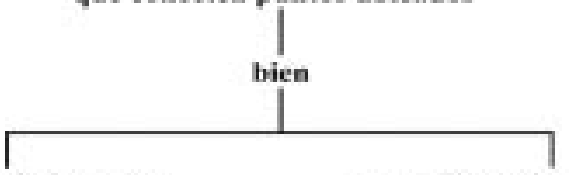

Donde el espesor de las rocas sedimentarias sea por lo menos el $1 \%$ de la distancia desde ese punto al pie del talud
A una distancia de hasta 60 millas mar afuera medidas desde el pie del taled costinental

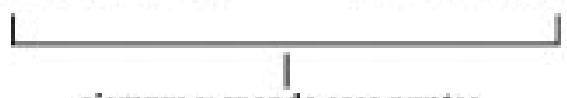

siempre y cuande esos puntos

no se encuentren más allá de

100 millas medidas desde - 350 millas desde las lineas de base la isóbata de 2,500 mts.<smiles>[131In][131In]</smiles>

En el caso de crestas sabmarinas que no sean componentes naturales del margen continental sólo podrả aplicarse el tope de las $\mathbf{3 5 0}$ millas 
de Referencia Terrestre del Servicio Internacional de Rotación de la Tierra ("ITRF 92").

Esto último era necesario para asegurar que el tratado pudiera ser aplicado uniformemente y con acuciosidad por México y Estados Unidos de América, respectivamente.

En el artículo III se asienta — por acuerdo entre las partes_, que México, al norte del límite de la Plataforma Continental (establecido en el artículo I), y Estados Unidos de América, al sur de dicho límite, no reclamarán ni ejercerán para ningún propósito derechos de soberanía o jurisdicción sobre el fondo marino y el subsuelo.

Además de lo consagrado anteriormente, el tratado contiene un nuevo conjunto de preceptos contenidos en los artículos IV y V, y que hacen referencia a la posible existencia de yacimientos de petróleo o gas natural a través del límite establecido para la Plataforma Continental.

Entre otras cosas, estos preceptos crean un marco jurídico (esperamos no —utópico-) por el cual las partes deberán intercambiar información para ayudar a determinar la posible existencia de "yacimientos transfronterizos".

Las partes se han comprometido (artículo IV) que durante una moratoria de 10 años, no autorizarán ni permitirán la perforación o la exploración petrolera o de gas natural en la Plataforma Continental dentro de una milla náutica, cuatro décimas (1.4) en cada lado de la frontera o límite establecido.

Por sus mismos términos, dentro de esta "área" de dos millas náuticas, ocho décimas (2.8), la moratoria no se aplica a otras actividades de la Plataforma Continental.

Esto quiere decir que cada parte tiene el derecho de autorizar o permitir la exploración y/o explotación de petróleo fuera del " rea" dentro de la Región Occidental.

Se establece igualmente, el que las partes podrán modificar, si así lo acuerdan, la moratoria de 10 años, a través de un canje de "notas" diplomáticas. Esta disposición permite a las partes de acortar o extender la duración de la moratoria, si así lo considerasen pertinente.

Otra disposición importante, en relación al rea, es la relativa al hecho de que si una parte tiene conocimiento de la existencia o de la posible existencia de un yacimiento transfronterizo, lo deberá notificar a la otra parte (artículo IV (6)).

A medida que se vaya generando la información geológica y geofísica que permita facilitar el conocimiento de las partes sobre la existencia 
de yacimientos transfronterizos, incluyendo las notificaciones de las partes sobre la posible existencia de los mismos (incluyendo el inciso 6o. del artículo IV), las partes deberán reunirse periódicamente con el fin de identificar, localizar y determinar las características geológicas y geofísicas de dichos yacimientos.

Toda controversia relativa a la interpretación o aplicación del tratado en cuestión, se debe resolver por negociación o por otros medios pacíficos que las partes acuerden.

El Tratado sobre Límites Marítimos entre Estados Unidos Mexicanos y Estados Unidos de América suscrito el 4 de mayo de 1978, y en vigor desde el 13 de noviembre de 1997, no había realizado la delimitación de los polígonos occidental y oriental (Western and Eastern Doughnut Hole), por lo que el presente tratado del 9 de junio de 2000 era necesario para dicho fin.

El área total del "polígono occidental" (western gap) es de aproximadamente 17,467 kilómetros cuadrados. El trazado de delimitación divide el polígono occidental de la Plataforma Continental, en forma tal, que Estados Unidos de América se adjudica 6,526 kilómetros cuadrados, es decir el 38\% del total, en tanto que a México le es adjudicado un área de 10,905 kilómetros cuadrados, esto es el 62\% del área total delimitada.

El Tratado sobre Límites Marítimos celebrado entre México y Estados Unidos de América el 4 de mayo de 1978, y aprobado por el Senado mexicano el 20 de diciembre del mismo año, durmió el sueño de los justos hasta que el Senado norteamericano tuvo a bien aprobarlo en octubre de 1997, e intercambiándose los instrumentos de ratificación el 13 de noviembre del mismo año.

El lapso increíble de casi 20 años que dejó pasar Estados Unidos de América, para finalmente aprobar y ratificar el tratado de 4 de mayo de 1978, se explica, simple y sencillamente, porque el extraordinariamente poderoso gremio petrolero norteamericano - encabezado por el geólogo Hollis Hedberg - se opuso rotundamente a que fuese aprobado, ya que se sostenía que tal tratado era contrario a los intereses de Estados Unidos de América, pues dejaba a México con un importante sector del Centro del Golfo de México que contenía un enorme potencial para la extracción de hidrocarburos y otros minerales. ${ }^{20}$

20 Véase Dillard, Hammetl, "Deepwater Drilling-Foresight, Risk and Reward", 22. Exploration and Ecónomics of the Petroleum Industry, USA, 1984, pp. 227-231. 
Estados Unidos de América enmendaron en forma significativa las leyes federales que gobiernan su sistema de pagos y patentes relativo a la producción "costa afuera" del gas e hidrocarburos, de forma tal que hicieron disminuir los obstáculos económicos, que habían dejado paralizados los extraordinarios avances tecnológicos.

Como resultado de la adopción de estas reformas, y en particular de la: “ Outer Continental Shelf Deep Water Royality Relief Act' (43.U.S.C.1337 (a)), adoptada en 1995, las compañías petrolíferas norteamericanas emprendieron un gran programa de exploración, al ver ahora reducidos sustancialmente los costos de producción.

Todo ello hacía necesario que Estados Unidos de América, ahora sí, quisiera aprobar y ratificar el Tratado de Límites de 1978 que había sido aprobado y ratificado por México de tiempo atrás.

Las asociaciones petrolíferas más poderosas de Estados Unidos de América, como la American Petroleum Institute; The International Association of Drilling Contractors; The Domestic Petroleum Council y otras más, urgían y presionaban ahora al Congreso norteamericano, para la ratificación del tratado de 1978, y para la celebración de un tratado para la Delimitación de la Plataforma Continental más allá de las 200 millas en el Golfo de México.

Ahora era imperativo poseer fronteras seguras, y delimitaciones marítimas precisas, para la instrumentación de los cuantiosos proyectos norteamericanos de exploración y explotación de yacimientos de hidrocarburos, gas y otros minerales en el Golfo de México. ${ }^{21}$

\section{CONCLUSIÓN}

Es cierto que la precisión que formula la Convención de Montego Bay de 1982, en el sentido de que el acuerdo de delimitación debe lograrse sobre la base del derecho internacional a que hace referencia el artículo 38 del Estatuto de la Corte Internacional de Justicia - Convenios y tratados internacionales; Normas consuetudinarias internacionales; Principios generales de derecho; y Decisiones judiciales y Doctrina calificada, como

21 Véase "Hearings on Maritime Boundaries Treaty with Mexico Before the Senate Committee On Foreign Relations”, 105th. Congress, 1s. Session, 1997 (Testimony of Frank Murkowski: Chairman of the Senate Committee on Energy and Natural Ressources). 
medio auxiliar-, no parece realmente aportar una contribución particularmente significativa al tema en cuestión.

Incluso, hay que decirlo, para buena parte de la doctrina la indicación de la solución equitativa aparece como igualmente insatisfactoria, "no estando claro cómo un acuerdo, que se presupone libremente convenido por las partes, pueda contener una solución no equitativa... La teoría de la solución equitativa representó un expediente feliz, elaborado por los tribunales internacionales" (profesor Tullio Scovazzi).

No es exagerado afirmar que la jurisprudencia en materia de delimitación marítima ha tomado el papel de las convenciones y de la costumbre, en el sentido de que la jurisprudencia en este ámbito aparece como una fuente directa y primaria, y no subsidiaria o auxiliar.

Sin embargo, no hay que olvidar que gran parte de la jurisprudencia en estos ámbitos ha tratado de conciliar el respeto de la soberanía territorial de Estados, con ciertos imperativos elementales de justicia, y en este sentido la búsqueda de la equidad normativa aparecía ciertamente como el mejor correctivo a una o varias reglas con componentes mucho muy rígidos e inflexibles.

Y, por último, es verdad, como han señalado varios jueces (N. Valti$\cos$ ), que Estados que han celebrado tratados bilaterales de delimitación de plataformas continentales probablemente no tenían el sentimiento de seguir una regla de derecho obligatoria ni estaban claramente inspirados por una opinio iuris.

No obstante lo anterior, los Estados han concertado tales tratados o acuerdos, a la luz de todas las reglas y datos jurídicos pertinentes; y pensando siempre que el método de la línea media, o línea de la equidistancia, era el sistema de delimitación más conveniente por sus cualidades inherentes, como son la relativa facilidad con que puede ser aplicada, y la determinación matemática que permite, antes de toda negociación, la fijación unilateral de una línea provisional. 


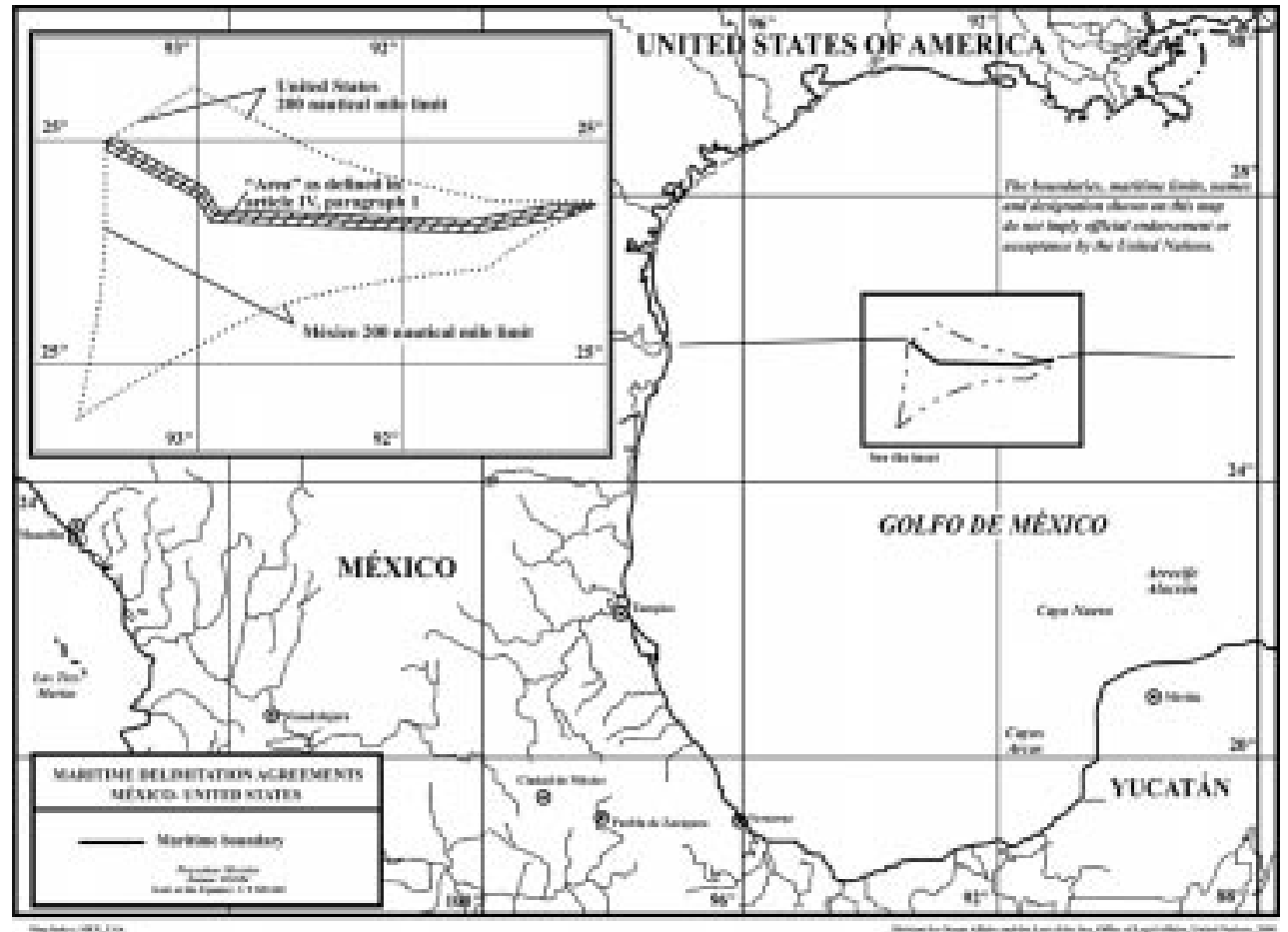

FUENTE: Law of the Sea, Boletín núm. 44, Nueva York, United Nations, 2001, p. 75. 


\section{LA EVOLUCIÓN DE LA DELIMITACIÓN DE LA PLATAFORMA CONTINENTAL EN EL DERECHO INTERNACIONAL Y EL CASO DE LA DELIMITACIÓN DEL POLÍGONO OCCIDENTAL ENTRE MÉXICO Y ESTADOS UNIDOS DE AMÉRICA}

\section{Susana HERNÁNDEZ PACHECO*}

Sumario: I. Introducción. II. Definición. III. Título jurídico. IV. Extensión. V. Concepto de delimitación marítima. VI. El régimen jurídico de la delimitación de la Plataforma Continental. VII. El caso de México y Estados Unidos de América.

\section{INTRODUCCIÓN}

La importancia de organizar esta mesa redonda radica en el carácter estratégico y fundamental del tema. Es estratégico debido a la existencia de importantes recursos naturales que se encuentran en la Plataforma Continental del Golfo de México, cuyo suelo está recubierto de recursos vegetales y animales, mientras que su subsuelo resguarda yacimientos petroleros y otros importantes minerales.

Si bien lo que motivó tanto a México como a Estados Unidos de América a celebrar el Tratado sobre la Delimitación de la Plataforma Continental en la Región Occidental del Golfo de México, más allá de las 200 millas náuticas, fue la sospecha de que existía un gran potencial petrolero en la región, la Plataforma Continental del Golfo de México cuenta además con otros recursos (perlas por ejemplo) que incrementan su importancia económica.

El estudio de este tema es además fundamental debido a sus implicaciones tanto económicas como jurídicas. En efecto, no se trata, como en el caso de la delimitación de las fronteras terrestres, que con títulos claramente reconocidos por el derecho internacional se determina hasta dónde llega el territorio de un Estado, sino que en el caso de la Plataforma Continental, desde su definición hasta su delimitación plantean problemas ju-

* Profesora de derecho internacional de la Facultad de Derecho de la UNAM. 
rídicos de difícil solución. Así, baste mencionar que el concepto de Plataforma Continental puede no coincidir en absoluto con su existencia física. Por otra parte, la determinación del límite exterior de la Plataforma Continental involucra no sólo a los Estados vecinos sino a la comunidad internacional. Además, dado que las facultades del Estado ribereño sobre su Plataforma Continental se limitan a fines de exploración y explotación, La delimitación lineal no parece determinante en los casos en que existan yacimientos minerales o petroleros transfronterizos que provoquen adecuaciones que "diluyan”, por así decirlo, la línea de delimitación.

\section{DEFINICIÓN}

La Plataforma Continental puede ser definida desde dos aspectos, uno geofísico y otro jurídico. Ambos conceptos toman en cuenta el aspecto físico de la Plataforma Continental, pero debido a que persiguen fines distintos, no necesariamente coinciden.

Los científicos definen la Plataforma Continental como una pendiente de inclinación variable que termina en una caída brusca hacia el fondo del mar. Desde el punto de vista geofísico, la Plataforma Continental se encuentra irregularmente distribuida en islas y continentes. En algunos lugares la Plataforma Continental alcanzará grandes distancias, mientras que en otros será prácticamente inexistente.

En su acepción jurídica, la noción de Plataforma Continental ha evolucionado en atención a la necesidad de regular las reivindicaciones estatales, con lo que se pretende por un lado limitar jurídicamente la posibilidad de exploración y de explotación de la Plataforma Continental por los Estados, y por otro, otorgar a todo Estado una Plataforma Continental independientemente de las características geológicas o geofísicas de la misma.

El origen de la noción jurídica de Plataforma Continental se remonta a la proclamación del presidente Truman, publicada por el gobierno de Estados Unidos de América el 28 de septiembre de 1945, cuyos principios sirvieron de base a los trabajos que culminarían con la Convención IV de Ginebra sobre Plataforma Continental.

De este modo, el derecho convencional definió la Plataforma Continental tomando primero en consideración criterios de profundidad y de explotabilidad. En términos del artículo 1o. de la Convención de 1958: 
La Plataforma Continental esta constituida por el lecho marino y el subsuelo de las regiones submarinas adyacentes a las costas, pero situadas fuera del mar territorial, hasta una profundidad de 200 metros, o más allá de este límite hasta el punto donde la profundidad de las aguas suprayacentes permitan la explotación de los recursos naturales de dichas regiones.

Esto implicaba que cualquier Estado que tuviera una mayor capacidad tecnológica de explotación, tendría mayor extensión de Plataforma Continental.

De acuerdo con la sentencia de la Corte Internacional de Justicia del 20 de febrero de 1969 emitida respecto de los Asuntos del Mar del Norte, ${ }^{1}$ la corte definió la Plataforma Continental como la prolongación natural del territorio del Estado, noción que sería la base del título que el derecho internacional reconoce como fundamento del derecho de los Estados sobre su Plataforma Continental.

Ahora bien, si la noción de 1958 favorecía a los países industrialmente desarrollados a causa del desarrollo tecnológico que éstos podían alcanzar, conceptuar la Plataforma Continental como la prolongación natural del territorio de un Estado planteaba el difícil problema de determinar hasta dónde llega la prolongación natural de un Estado con relación a la prolongación natural de otro Estado, y el de qué hacer si una Plataforma Continental resulta la prolongación natural de dos o mas Estados. En todo caso la jurisprudencia internacional no ha reconocido plenamente los efectos de esta definición. Así, si bien el fundamento conceptual de la Plataforma Continental sigue siendo el de la prolongación natural del territorio de un Estado bajo el mar, el derecho internacional impone un límite a dicha prolongación.

El desarrollo de tecnologías que permitieron explotar de manera más importante los recursos marinos, originó un cambio del concepto. De la idea de profundidad y explotabilidad se pasó a la de distancia. Sin abandonar del todo el concepto de prolongación natural, la Convención de las Naciones Unidas sobre el Derecho del Mar en su artículo 76 establece:

1. La Plataforma Continental de un Estado ribereño comprende el lecho y el subsuelo de las áreas submarinas que se extienden más allá de su mar territorial y a todo lo largo de la prolongación natural de su territorio hasta

1 Cfr. Asuntos de la Plataforma Continental del Mar del Norte (República Federal Alemana/Dinamarca y República Federal Alemana/Países Bajos), CIJ, Recueil des Arrets, Avis Consultatifs et Ordennances, sentencia de 20 de febrero de 1969, p. 32. 
el borde exterior del margen continental, o bien hasta una distancia de 200 millas marinas contadas desde las líneas de base, a partir de las cuales se mide la anchura del mar territorial, en los casos en que el borde exterior del margen continental no llegue a esa distancia... 3. El margen continental comprende la prolongación sumergida de la masa continental del Estado ribereño y está constituido por el lecho y el subsuelo de la plataforma, el talud y la emersión continental. No comprende el fondo oceánico profundo con sus crestas oceánicas ni su subsuelo.

\section{TÍTULO JURÍDICO}

Tal como lo señaló la Corte Internacional de Justicia en su sentencia del 20 de febrero de 1969, el título jurídico que el derecho internacional reconoce al Estado sobre su Plataforma Continental no deriva de la proximidad de ésta, sino de la noción de prolongación natural del territorio del Estado. La corte se expresó en estos términos:

El título que el derecho internacional atribuye ipso jure al Estado ribereño sobre su Plataforma Continental procede de que las zonas submarinas en cuestión pueden ser consideradas como siendo verdaderamente parte del territorio, sobre el cual el Estado ribereño ejerce ya su autoridad: se puede decir que, aun cuando recubiertas de agua, dichas zonas son una prolongación, una continuación, una extensión de dicho territorio bajo el mar. ${ }^{2}$

De acuerdo con esta noción, no importa que la Plataforma Continental de un Estado esté más próxima a la frontera de otro Estado, si constituye la prolongación natural de su territorio, podrá válidamente reivindicarla. Sin embargo la evolución del concepto de Plataforma Continental ha llevado a establecer un criterio de distancia, por lo que es ésta y no la idea de prolongación natural la base del título jurídico, al menos hasta las 200 millas marinas. $^{3}$

\section{EXTENSIÓN}

La Convención de 1958, reguló la extensión de la Plataforma Continental atendiendo a factores de profundidad y de capacidad de explota-

2 Idem.

3 Cfr. Asunto de la Plataforma Continental (Jamahiriya Árabe Libia/Malta), CIJ, Recueil des Arrets, Avis Consultatifs et Ordennances, sentencia del 3 de junio de 1985, p. 35. 
ción de los Estados. Esto es, hasta una profundidad de 200 metros, o hasta donde las aguas suprayacentes permitan su explotación.

El acelerado desarrollo tecnológico que alcanzaron ciertos Estados, así como el hecho de que la Convención de Ginebra de 1958 sólo es obligatoria para los Estados parte de la misma, condujo a la elaboración de una definición jurisprudencial que la consideró como la prolongación natural del territorio que permitía reivindicaciones basadas en aspectos predominantemente físicos y no jurídicos. Tal situación llevó a que en la Tercera Conferencia de las Naciones Unidas sobre el Derecho del Mar se modificara esta concepción y se limitara a 200 millas náuticas la extensión de la Plataforma Continental, independientemente de su estructura física, con la posibilidad de extenderla hasta un máximo de 350 millas marinas, cuando la Plataforma Continental llegue hasta esa distancia.

De acuerdo con la Convención de Montego Bay, si la extensión de la Plataforma Continental llega hasta 350 millas náuticas, para que la delimitación que se haga con base en dicha extensión sea oponible a los demás Estados deberá informarse a la Comisión de Límites que la propia convención prevé. Cuando los Estados son adyacentes o se encuentran frente a frente, la delimitación deberá realizarse por acuerdo entre las partes, de conformidad con el derecho internacional, con el objeto de llegar a una solución equitativa. En algunos de estos casos la extensión de la Plataforma Continental podría no llegar siquiera a las 200 millas, como en el caso de la Plataforma Continental entre Libia y Malta, ${ }^{4}$ o extenderse más allá de esa distancia, como en el caso de Estados Unidos de América y México en el Golfo de México.

\section{CONCEPTO DE DELIMITACIÓN MARÍTIMA}

La delimitación, dijo la corte en 1969, consiste en determinar los límites de una zona dependiente ya del Estado costero, y no en una operación que pretendiera definir dicha zona de novo. ${ }^{5}$ Es decir no se trata de un reparto de la región en cuestión sino de estrictamente una delimitación.

La delimitación de la Plataforma Continental podrá realizarse de manera unilateral sólo cuando el Estado en cuestión no tenga vecinos frente

5 Ibidem, p. 23. 
a él o adyacentes, pero para que ésta delimitación les sea oponible a los demás Estados, deberá hacerse conforme al derecho internacional. Se trata pues, como afirma Michel Virally, de una delimitación entre un Estado y la comunidad internacional. ${ }^{6}$

En el caso de los Estados adyacentes o que se encuentren situados frente a frente, el derecho convencional ha establecido la obligación de que dicha delimitación se realice por acuerdo entre las partes con base al derecho internacional, con el fin de llegar a una solución equitativa.

\section{EL RÉGIMEN JURÍDICO DE LA DELIMITACIÓN DE LA PLATAFORMA CONTINENTAL}

Toda delimitación marítima debe hacerse conforme al derecho internacional. Sin embargo, saber cuáles son las normas de derecho que regulan la delimitación de la Plataforma Continental entre Estados es un problema que no ha sido resuelto de manera satisfactoria.

La Corte Internacional de Justicia y los tribunales arbitrales que han fallado en la materia han determinado que cada caso es un unicum, y por lo tanto no hay principios generales, el problema, señaló la corte en 1984, es que "se quiere encontrar en el derecho internacional general una especie de serie de reglas que no existen".?

En consecuencia, cada delimitación de la Plataforma Continental es un caso único y debe ser resuelto en función de las circunstancias que le son propias. ${ }^{8}$

Tanto el derecho convencional como el derecho consuetudinario han pretendido regular la delimitación de la Plataforma Continental. Su contenido, sin embargo, no permite conocer de qué manera debe realizarse dicha delimitación. Existe en efecto, una tendencia hacia la abstracción que evita la formación de normas de fondo que guíen a los juristas que, como jueces o árbitros, o como negociadores, deban realizar esa tarea.

Las normas de derecho internacional que regulan la delimitación de la Plataforma Continental son la Convención de 1958 sobre Plataforma

6 Virally, Michel, "L'Equité dans le droit. A propos des problèmes de delimitation maritime", Le droit international a l'heure de sa codification. Etudes en l'honneur de Roberto Ago, vol. II, Milán-Dott. A. Giuffrè editore, 1987, p. 531.

7 Caso de la Delimitación de la Frontera Marítima en la Región del Golfo de Maine (Canadá/Estados Unidos de América), CIJ, Recueil des Arrets, Avis Consultatifs et Ordennances, sentencia de 12 de octubre de 1984, p. 290.

8 Cfr. idem. 
Continental, la Convención de Naciones Unidas sobre el Derecho del Mar de 1982 y el derecho consuetudinario, que ha sido reconocido a través de la jurisprudencia internacional en la materia.

La convención de Ginebra de 1958 en su artículo 6o. establecía el criterio según el cual, a falta de acuerdo entre las partes, debía aplicarse el método de equidistancia ${ }^{9}$ para los Estados que se encuentran frente a frente, y de la línea media para los Estados adyacentes, a menos que circunstancias especiales impidieran su aplicación.

Sin embargo, cuando en 1969 se presentó el primer asunto para ser resuelto por la Corte Internacional de Justicia, en el que se le solicitaba determinar cuál era el derecho aplicable a la delimitación de la Plataforma Continental en el Mar del Norte, se puso en evidencia que no necesariamente era un método adecuado en toda circunstancia y, sobre todo, la corte, después de un razonamiento sobre la formación de la costumbre internacional, concluyó que no tenía el carácter de norma consuetudinaria, y por lo tanto no tenía aplicación general; conclusión a la que también llegó el Tribunal Arbitral constituido para dirimir el asunto de la delimitación de la Plataforma Continental en el Mar de Iroise. ${ }^{10}$

Para saber cuáles son los principios de carácter general aplicables en la materia, es necesario acudir a las fuentes auxiliares del derecho internacional, entre las cuales la jurisprudencia ha tenido una importancia fundamental, hasta el punto de ser considerada por algunos doctrinarios, ya no como una fuente auxiliar sino principal del derecho internacional. ${ }^{11}$

La Corte Internacional de Justicia, en su sentencia de 1969, haciendo un análisis de la formación del derecho consuetudinario y tomando como base la conducta de los Estados respecto de la delimitación de su Plataforma Continental, estableció que tal delimitación:

Debe operar por acuerdo conforme a principios equitativos, tomando en cuenta todas las circunstancias pertinentes, de manera que se atribuya, en la medida de lo posible, a cada parte la totalidad de las zonas de Plataforma

9 La equidistancia se obtiene a través del trazo de una línea, cuyos puntos de encuentren a una distancia igual de los puntos de referencia tomados de la línea de base a partir de la cual se mide la anchura del mar territorial de ambos Estados.

10 Asunto de la Delimitación de la Plataforma Continental (Reino Unido de Gran Bretaña e Irlanda del Norte/República Francesa), CIJ, Recueil des Sentences Arbitrales, vol. XVIII, Naciones Unidas, párrafo 75 .

11 Cahier, Philippe, "Les sources du droit relatif à la delimitation du plateau continental", en Le droit au service de la paix, de la justice et du developpement, París, Pedone, 1991, p. 181. 
Continental que constituyen la prolongación natural de su territorio bajo el mar, y no empalmando sobre la prolongación natural del territorio del otro. $^{12}$

Este razonamiento fundado en la libre apreciación de las circunstancias pertinentes fue confirmado por el tribunal arbitral que resolvió la controversia sobre la frontera marítima entre Guinea y Guinea Bissau en su sentencia de 14 de febrero de 1985, que determinó que: "Tratándose de factores, el tribunal debe inventariarlos y apreciarlos... Estas circunstancias no serán tomadas en cuenta por el tribunal, sino cuando éste las juzgue pertinentes en el caso concreto". ${ }^{13}$

Esto es, de la singularidad o particularidad de una circunstancia que puede excluir la delimitación equidistante, se pasa a la aplicación de principios equitativos, debiendo tomar las circunstancias conducentes, es decir, sólo aquellas que ameriten ser tomadas en cuenta. Así, una circunstancia especial puede no ser considerada pertinente. ${ }^{14}$

De este modo, la norma que establece como método de delimitación un acuerdo entre las partes o, a falta de éste, el método de equidistanciacircunstancias especiales, se ve vaciada de su contenido, al establecerse la fórmula principios equitativos-circunstancias pertinentes, sobre todo, considerando, como lo hizo la sala de la corte en 1984 en el asunto de la Delimitación Marítima del Golfo de Maine que tales principios equitativos "no son en sí mismos reglas de derecho". ${ }^{15}$ Estos principios equitativos regularían tanto la delimitación como la elección del método práctico para realizarla. Es decir, se deja a la consideración del juez la determinación del método aplicable ${ }^{16}$ "sobre la base de la regla fundamental que prescribe que la delimitación sea conforme a principios equitativos". ${ }^{17}$

Ahora bien, si la elección del método práctico de delimitación debe realizarse con base en principios equitativos no obligatorios, tomando en

12 CIJ, Recueil des Arrets..., cit., nota 1, p. 53.

13 Tribunal Arbitral para la Delimitación de la Frontera Marítima (Guinea/Guinea Bissau), Recueil des Sentences Arbitrales, sentencia del 14 de febrero de 1985, párrafo 89.

14 Véanse, por ejemplo, los factores económicos en el Asunto de la Plataforma Continental (Jamahiriya Árabe Libia/Malta), CIJ, Recueil des Arrets..., cit., nota 3, p. 4.

15 CIJ, Recueil des Arrets..., cit., nota 7, p. 292.

16 Esos métodos prácticos pueden ser la línea perpendicular a la costa, la línea siguiendo la dirección general de la costa, la línea de equidistancia, etcétera.

17 CIJ, Recueil des Sentences Arbitrales, Arbitraje sobre la Delimitación de la Plataforma Continental en el Mar D’ Iroise, párrafo 99. 
cuenta sólo las circunstancias pertinentes, el objetivo final que es la delimitación, debe llegar a un resultado equitativo. Así, la fórmula acuerdoprincipios equitativos-circunstancias pertinentes, se ve completada por un último elemento: el del resultado equitativo: "La aplicación de principios equitativos debe lograr un resultado equitativo... ya que el adjetivo equitativo está calificando a la vez el resultado que se tiende a lograr, y los medios por los cuales se pretende llegar a ese fin. La equidad de un principio debe apreciarse de acuerdo a la utilidad que representa para lograr un resultado equitativo". ${ }^{18}$

Más tarde se pasa de la fundamentalidad de los principios equitativos al discernimiento de los criterios. Así, en 1984, la Corte Internacional de Justicia se expresó en los siguientes términos: "El derecho internacional establece únicamente que la delimitación debe realizarse por la aplicación de criterios equitativos y por utilización de métodos prácticos aptos a asegurar, tomando en cuenta la configuración geográfica de la región y otras circunstancias pertinentes en el caso, un resultado equitativo". ${ }^{19}$

El camino hacia la abstracción es pues, evidente.

Para la sala, lo que el derecho internacional prescribía era sólo inspirarse en cada caso concreto, del criterio o del equilibrio de criterios diferentes, que pareciesen como más apropiados a la situación concreta. Este razonamiento fue confirmado en el Asunto entre Malta-Libia, ${ }^{20}$ en donde la corte vuelve a establecer que la delimitación de la Plataforma Continental debe realizarse conforme a principios equitativos y habida cuenta de todas las circunstancias pertinentes, con el fin de lograr un resultado equitativo.

Para conseguir esa solución equitativa, los principios equitativos, que ya habían sido desprendidos de obligatoriedad, van a ser calificados de acuerdo con su utilidad para llegar a la esperada solución equitativa: "La equidad de un principio debe ser apreciado de acuerdo a la utilidad que presente para llegar a un resultado equitativo. Todos los principios no son en sí equitativos: es la equidad de su solución que les confiere esta cualidad". ${ }^{21}$

18 Asunto de la Plataforma Continental (Túnez/Jamahiriya Árabe Libia), CIJ, Recueil des Arrets, Avis Consultatifs et Ordennances, sentencia de 24 de febrero de 1982, p. 59.

19 CIJ, Recueil des Arrets..., cit., nota 7, p. 300.

20 Cfr. CIJ, Recueil des Arrets..., cit., nota 3.

21 CIJ, Recueil des Arrets..., cit., nota 18, p. 45. 
Habrá que distinguir entonces, entre principios o criterios equitativos no vinculatorios y "que no pueden ser objeto de una definición sistemática a priori" ${ }^{22}$ de los factores o circunstancias pertinentes que atienden a situaciones geográficas de la región. Aunque "en realidad no hay límites jurídicos a las consideraciones que los Estados puedan examinar a fin de asegurarse que van aplicar procedimientos equitativos". ${ }^{23}$

No existe por tanto, norma jurídica que establezca cuáles son los principios equitativos con base en los cuales debe realizarse la delimitación, ni cuál el método práctico que debe aplicarse para el mismo fin, lo importante es llegar a una solución equitativa.

Finalmente, la Convención de Naciones Unidas sobre el Derecho del Mar de 1982, ya no hace referencia a los principios equitativos, sino que pone énfasis en el resultado equitativo al que debe llegarse en toda delimitación de la Plataforma Continental. En efecto, el artículo 83, numeral 1 dispone: "La delimitación de la Plataforma Continental entre Estados con costas adyacentes o situadas frente a frente se efectuará por acuerdo entre ellos sobre la base del derecho internacional, a que se hace referencia en el artículo 38 del Estatuto de la Corte Internacional de Justicia, a fin de llegar a una solución equitativa".

Esta regla ha sido considerada como un reflejo del derecho consuetudinario en la materia. Así lo determinó la Corte Internacional de Justicia en 1993 al señalar: "La indicación de una 'solución equitativa' como fin de toda operación de delimitación refleja las exigencias del derecho consuetudinario en lo que se refiere a la delimitación de la Plataforma Continental". ${ }^{24}$

En consecuencia, el único principio general aplicable es el que establece que la delimitación de la Plataforma Continental entre Estados debe hacerse por vía de acuerdo entre las partes, y a falta de éste a través de la resolución de una instancia judicial, con el fin de llegar a un resultado equitativo, lo que ha permitido expresar a algunos autores que la norma del derecho que obliga a alcanzar una solución equitativa, es en realidad una norma vacía, en el sentido de que no señala la manera de llegar a ese resultado.

22 CIJ, Recueil des Arrets..., cit., nota 7, p. 33.

23 CIJ, Recueil des Arrets..., cit., nota 1, p. 93.

24 Asunto de la Delimitación Marítima en la Región situada entre Groenlandia y Jan Mayen (Dinamarca/Noruega), CIJ, Recueil des Arrets, Avis Consultatifs et Ordennances, sentencia de 14 de junio de 1993, p. 25. 
Por otra parte, la referencia al derecho internacional no auxilia en nada las operaciones de delimitación de la Plataforma Continental, ya sea por los Estados negociadores o los jueces y árbitros llamados a realizarlas, pues como se ha visto, esas normas jurídicas no proporcionan reglas de fondo. Esta situación ha sido resaltada por la Corte Internacional de Justicia, quien ha señalado que los textos convencionales "dan una definición de la regla de derecho internacional en materia de delimitación", ${ }^{25}$ sin dejar de advertir sobre precario contenido material de esos artículos. ${ }^{26}$

Se trata pues de una norma jurídica que remite a la equidad, aunque la corte ha aclarado que "no se trata aplicar la equidad simplemente como una representación de la justicia en abstracto, sino de aplicar una regla de derecho que prescribe recurrir a principios equitativos conforme a las ideas que siempre han inspirado el desarrollo del régimen jurídico de la Plataforma Continental". ${ }^{27} \mathrm{El}$ procedimiento que ha establecido la jurisprudencia internacional es el siguiente: precisar el área que va a ser objeto de la delimitación; enlistar las circunstancias que deben ser tomadas en cuenta para luego valorarlas, y definir cuál es el peso que debe darse a cada una de ellas; trazar posteriormente una línea provisional, cuyo resultado equitativo se verifica al final del procedimiento.

Sin embargo, saber cuál es ese resultado equitativo es todavía una cuestión sin resolver.

\section{EL CASO DE MÉXICO Y ESTADOS UNIDOS DE AMÉRICA}

La delimitación de la Plataforma Continental en el Golfo de México involucra a tres Estados: México, Estados Unidos de América y Cuba. El derecho internacional establece el derecho de los Estados a una Plataforma Continental de 200 millas contadas a partir de las líneas de base a partir de las cuales se mide la anchura del mar territorial, independientemente de la conformación geológica de dicha plataforma. En el caso del Golfo de México, la Plataforma Continental se extiende a más de 400 millas, por lo que la delimitación de dicha plataforma no compromete las 200 millas de cada uno de los Estados.

26 CIJ, Recueil des Arrets..., cit., nota 18, p. 49; CIJ, Recueil des Arrets..., cit., nota 7, p. 30.

27 CIJ, Recueil des Arrets..., cit., nota 1, p. 47. 
La delimitación de la Plataforma Continental hasta las 200 millas entre México y Estados Unidos de América se realizó por acuerdo, a través del Tratado sobre Límites Marítimos de 1978, quedando pendiente de delimitar la región central del Golfo de México, más allá de las 200 millas de cada Estado.

De acuerdo con el artículo 76, numerales 4 y 5 de la Convención de Montego Bay, en los casos de que el borde exterior del margen continental se extienda más allá de las 200 millas marinas contadas a partir de las líneas de base a partir de las cuales se mide la anchura del mar territorial, los puntos fijos que constituyen la línea del límite exterior de la Plataforma Continental al lecho del mar deberán ser trazadas a una distancia que no exceda de las 350 millas marinas contadas desde las líneas de base a partir de las cuales se mide la anchura del mar territorial, o de 100 millas marinas contadas desde la isóbata de 2,500 metros que es una línea que une una profundidad de 2,500 metros.

La delimitación de la Plataforma Continental entre México y Estados Unidos de América más allá de las 200 millas náuticas fue realizada por el Tratado sobre la Delimitación de la Plataforma Continental en la Región Occidental del Golfo de México más allá de las 200 Millas Náuticas. ${ }^{28}$ Este tratado impone varias reflexiones. Aunque la noción de Plataforma Continental como prolongación natural del territorio de un Estado tiene aplicación más allá de las 200 millas náuticas, los Estados no la consideraron como base de sus negociaciones, sino que éstas se realizaron con base en estudios que determinaron el potencial petrolero de la región.

Por otra parte, de acuerdo con el numeral 8 del artículo 76, de la Convención de Naciones Unidas sobre el Derecho del Mar:

El Estado ribereño presentará información sobre los límites de la Plataforma Continental más allá de las 200 millas marinas contadas a partir de las líneas de base a partir de las cuales se mide la anchura del mar territorial a la Comisión de Límites de la Plataforma Continental, establecida de conformidad con el Anexo II sobre la base de una representación geográfica equitativa, la Comisión hará recomendaciones a los Estados ribereños so-

28 Este tratado fue firmado en Washington el 9 de junio de 2000. El canje de instrumentos de ratificación previsto en el artículo IX del tratado se realizó en la ciudad de México el 17 de 2001, y fue publicado en el Diario Oficial de la Federación el 22 de marzo de 2001. 
bre las cuestiones relacionadas con la determinación de los límites exteriores de su Plataforma Continental. Los límites de la plataforma que determine un Estado ribereño, tomando como base tales recomendaciones, serán definitivos y obligatorios.

Sin embargo, dado que sólo México es parte de la Convención de 1982, esta obligación no podría serle impuesta a Estados Unidos de América, debido a que los tratados sólo son obligatorios para las partes, a menos que la evolución del derecho del mar permita considerar esta norma como parte del derecho internacional general.

El tratado tiene como objeto la delimitación de la Plataforma Continental en el polígono occidental del Golfo de México, la cual queda establecida en el artículo 1o. Sin embargo, además de la delimitación se establece un régimen de reuniones y de consultas, así como de cooperación mutua en relación con estudios geológicos y geofísicos que conduzcan a ubicar yacimientos transfronterizos en lo que se denomina "el área", es decir 1.4 millas náuticas de cada uno de los lados del límite marcado por el artículo 1o. Así por ejemplo, el artículo IV, debido a la posible existencia de yacimientos transfronterizos de petróleo o gas natural, las partes se comprometen a no autorizar ni permitir la perforación o la explotación petrolera o de gas natural en la Plataforma Continental en dicha "área", por un periodo de diez años a partir de la entrada en vigor del tratado. El derecho internacional reconoce a los Estados soberanía con el fin de exploración y explotación de los recursos naturales, tales derechos son exclusivos pero en el caso de que los recursos naturales del suelo y subsuelo no permiten una división lineal, el concepto mismo de exclusividad parece poco adecuado.

Esto significa que la delimitación tradicional a través de una línea no puede ser plenamente aplicado para la Plataforma Continental, cuando en ella existen yacimientos transfronterizos. En efecto, si deben compartirse esas facultades de exploración, aunque sea bajo una obligación convencional de autorización, la línea de delimitación se transforma en un área de cooperación de exploración entre los Estados. Tal parece que los principios que el derecho internacional ha desarrollado sobre la Plataforma Continental son rebasados por una realidad geofísica que no se presta a la regulación jurídica.

Por otra parte, resta saber si se llegó al resultado equitativo que establece el derecho internacional. En principio, dado que los Estados llega- 
ron a un acuerdo sin necesidad de recurrir a los medios pacíficos de solución de controversias, podremos concluir que ambos coinciden en un resultado equitativo. La cuestión de saber cómo llegar a ese resultado equitativo tendrá una mayor importancia en la delimitación del polígono oriental del Golfo de México, delimitación en la que participarán Estados Unidos de América; México y Cuba. 


\section{PROYECTO POLÍGONO OCCIDENTAL*}

\section{Mario LIMÓN GONZÁLEZ**}

SuMARIO: I. Objetivo. II. Antecedentes. III. Generalidades. IV. Marco geológico regional. V. Columna geológica. VI. Interpretación. VII. Líneas en tiempo. VIII. Líneas en profundidad. IX. Mapas de configuración en profundidad de las unidades Challenger y Cordilleras Mexicanas. X. Geología petrolera. XI. Evaluación de los recursos petroleros potenciales. XII. Método de balance de masas. XIII. Yacimientos transfronterizos.

XIV. Conclusiones.

\section{OBJETIVO}

Definir las características geológicas del polígono occidental para evaluar sus recursos petroleros potenciales.

\section{ANTECEDENTES}

Con motivo de la negociación y firma del tratado sobre los límites marítimos entre México y Estados Unidos de América en 1978, la Asociación Americana de Geólogos Petroleros (AAPG), propuso en 1979 una modificación al acuerdo de delimitación marítima entre ambos países, la cual sugería un cambio en los límites para las pláticas del tratado de 1978, debido al potencial petrolero que ellos suponían para esta porción de la cuenca del Golfo de México (véase figura 1 en la página siguiente). De acuerdo con esta propuesta, gran parte de las áreas de la Planicie Abisal, delimitada por la isóbata de 3,000 m, una porción del Cinturón Plegado Perdido, los montículos Sigsbee, una parte del Escarpe de Sigsbee, y

* Este trabajo es el resultado de las investigaciones realizadas para la negociación del Tratado sobre la Delimitación de la Plataforma Continental en la Región Occidental del Golfo de México más allá de las 200 Millas Náuticas.

** Gerente de Proyectos Interregionales y Áreas Nuevas de Pemex, Exploración y Producción. 


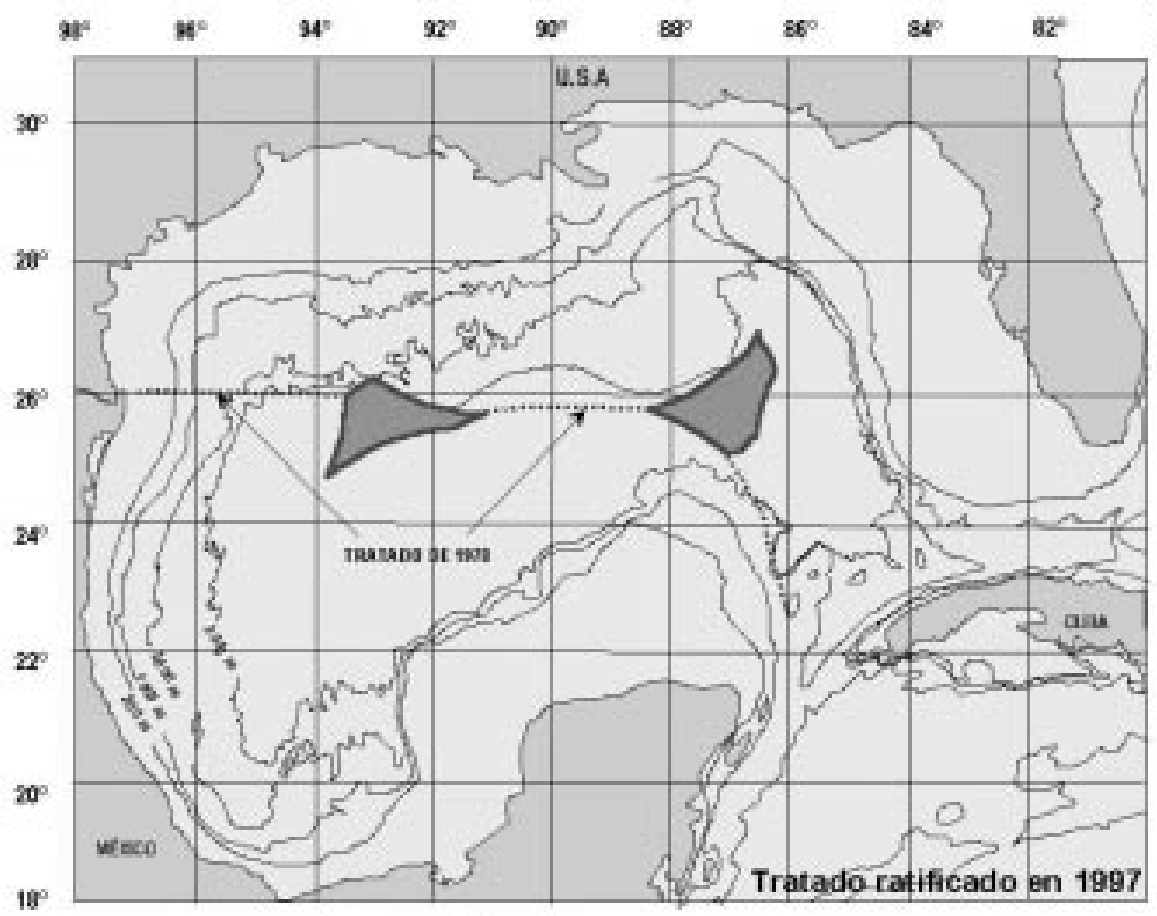

Fig. 1 
una parte de la plataforma continental quedarían en aguas internacionales, y por lo tanto se tendrían que negociar con México.

Como resultado de esta propuesta, el senado estadounidense difirió la firma del Tratado de Límites Marítimos entre México y Estados Unidos de América y dos años más tarde, en 1981, el Departamento del Interior de Estados Unidos de América realizó a través del Servicio Geológico de este mismo país un estudio regional para evaluar el potencial petrolero en las áreas propuestas por la AAGP. Dicho estudio fue denominado "La Región de la Frontera Marítima en el Centro del Golfo de México".

La región evaluada en ese estudio fue dividida en seis áreas con base en sus características geológicas (véase figura 2 en la página siguiente):

\section{Planicie Abisal.}

2. Margen del Río Grande.

3. Cinturón Plegado Perdido.

4. Escarpe de Sigsbee.

5. Montículos de Sigsbee.

6. Escarpe de Campeche.

Estas áreas están en tirantes de agua que varían de $30 \mathrm{~m}$ a 3,750 m, con más del $75 \%$ de la superficie total bajo tirantes de agua que exceden $\operatorname{los} 3,000 \mathrm{~m}$.

Cabe aclarar que las seis áreas evaluadas en dicho estudio, según se ilustra en la figura 2, constituyen únicamente una porción de las provincias geológicas a las que están referidas.

Los resultados de tal estudio fueron publicados por la AAGP en 1983, en donde se indica que los volúmenes de hidrocarburos in situ se calcularon con base en un análisis geológico y con una metodología probabilística.

El potencial estimado como valores medios en dicho estudio se presenta en la figura 2. Respecto a estas estimaciones es pertinente hacer notar que los volúmenes de aceite y gas in situ se refieren a todo el petróleo que puede haber en los espacios porosos de las rocas acumuladoras, sin considerar qué fracción se puede o se podría producir (reservas) y sin tomar en cuenta limitaciones económicas o tecnológicas. Como una referencia de esta estimación in situ, el Servicio Geológico de Estados Unidos de América cita que en este país aproximadamente $32 \%$ del aceite in situ se puede producir, mientras que el $80 \%$ del gas in situ se puede recuperar. 


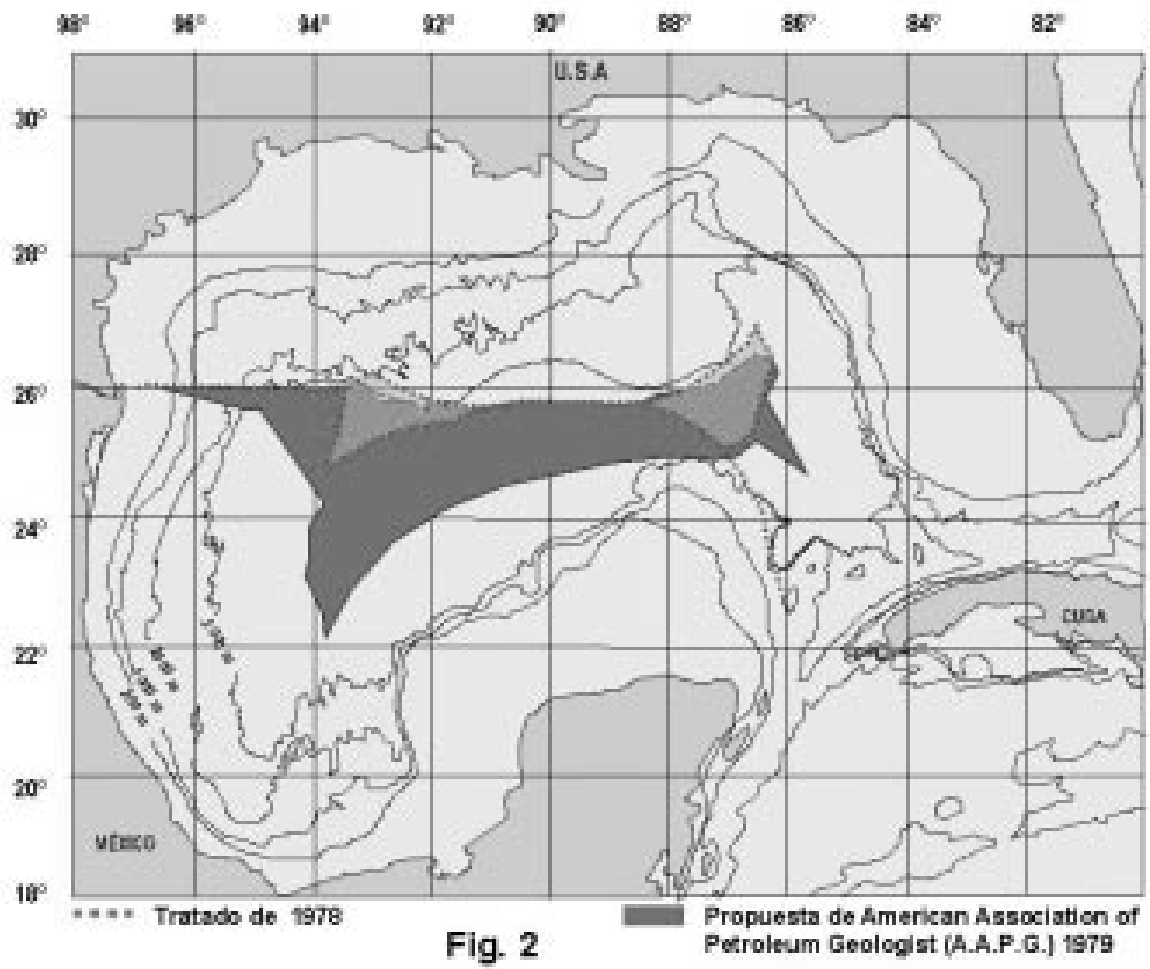


Después de ese estudio, el senado estadounidense mantuvo suspendida la firma del tratado de 1978, y no fue sino hasta noviembre de 1997 que se ratificó dicho tratado, por lo que permanecieron los límites como se habían pactado originalmente (véase figura 3 en la página siguiente), quedó pendiente la negociación de las áreas que se conocen como "Polígono Occidental" y "Polígono Oriental".

En 1998, México y Estados Unidos de América empezaron pláticas para establecer los límites entre ambos países en el Polígono Occidental. Para este fin se encomendó a Petróleos Mexicanos realizar un estudio del potencial petrolífero del área, y en este trabajo se presentan los resultados obtenidos.

\section{GENERALIDADES}

El Polígono Occidental se ubica en la parte central del Golfo de México entre los paralelos 2630 y $2430 \mathrm{~N}$ y los meridianos 9045 y $9400 \mathrm{~W}$ y tiene una superficie de $16,700 \mathrm{~km}$, correspondiendo en su mayor parte a la Planicie Abisal (87\%) y una pequeña porción al Escarpe de Sigsbee (13\%) y queda ubicado en tirantes de agua que varían entre los 2,100 $\mathrm{m}$ y los 3,700 m (véase figura 4 infra p. 93).

Para tener una buena imagen de las características geológicas del subsuelo es necesario contar con la información sísmica de reflexión de buena calidad. El procedimiento utilizado en este caso fue empleando la tecnología más avanzada y los resultados fueron de alta calidad.

En el área del Polígono Occidental se cuenta con 2,300 kms. lineales de información sísmica bidimensional; $980 \mathrm{kms}$. obtenidos de la Compañía Tensor Geophysical Services (TGS), que se dedica a hacer trabajos de adquisición de datos sísmicos en el ámbito mundial; complementada con parte de un trabajo sísmico regional realizado por Pemex, Exploración y Reproducción, en el trimestre septiembre-noviembre de 1998 (véase figura 5 infra p. 94), que consistió en el levantamiento de 3,000 kms. lineales, de los cuales una malla de 18 líneas sísmicas, que totalizan 1,300 kms. lineales cubre todo el polígono, con un espaciamiento promedio entre líneas de $20 \mathrm{kms}$. y una longitud de grabación de 12 segundos. Esto último equivale a registrar profundidades en el subsuelo de más de 14,000 metros bajo el nivel del mar (mbnm). 


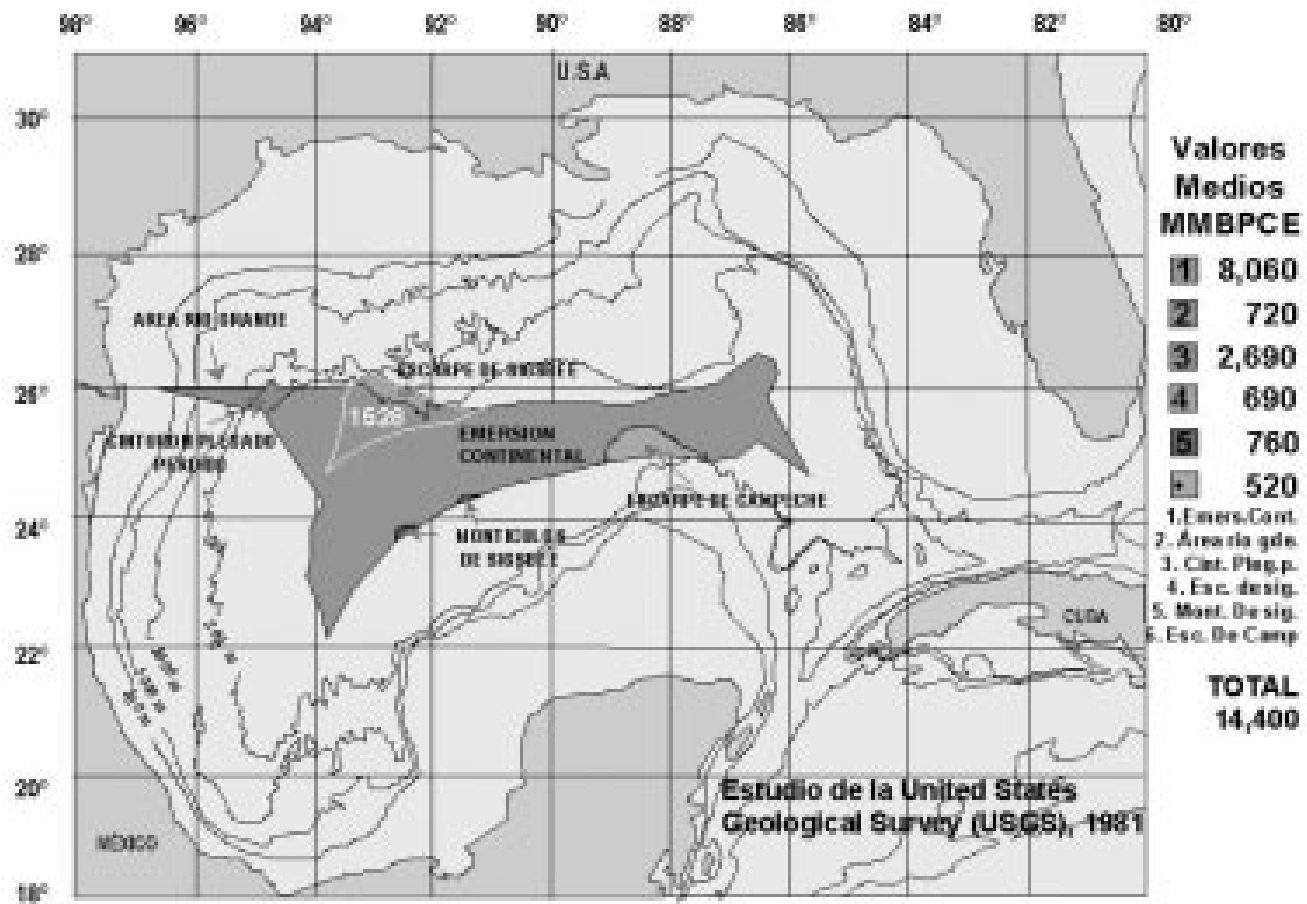

$5000 \rho c g=1$ BPCE

Fig. 3

"Regón de la Frontera Maílima en el centro del Golfo de México" 


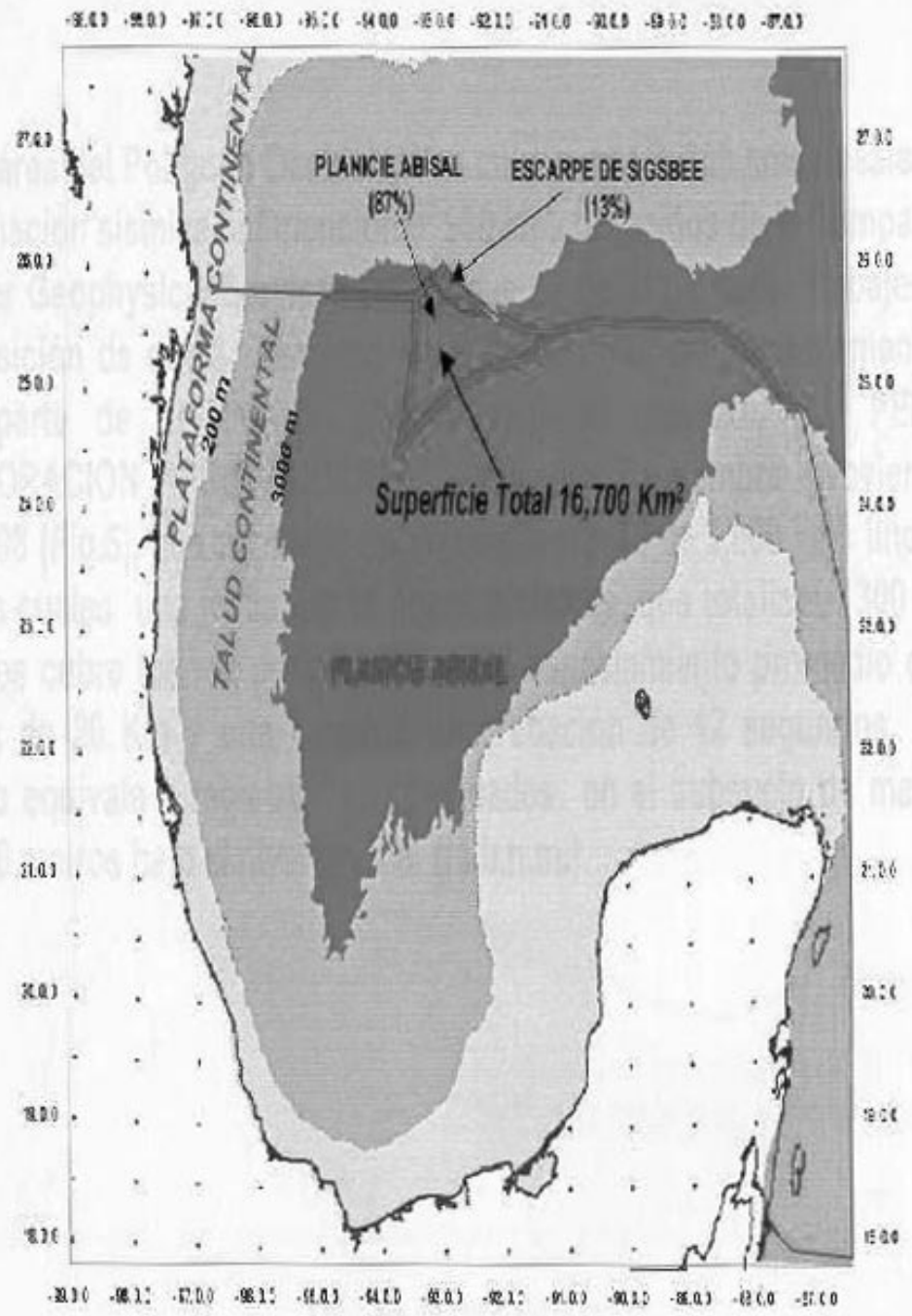

Fig. 4 


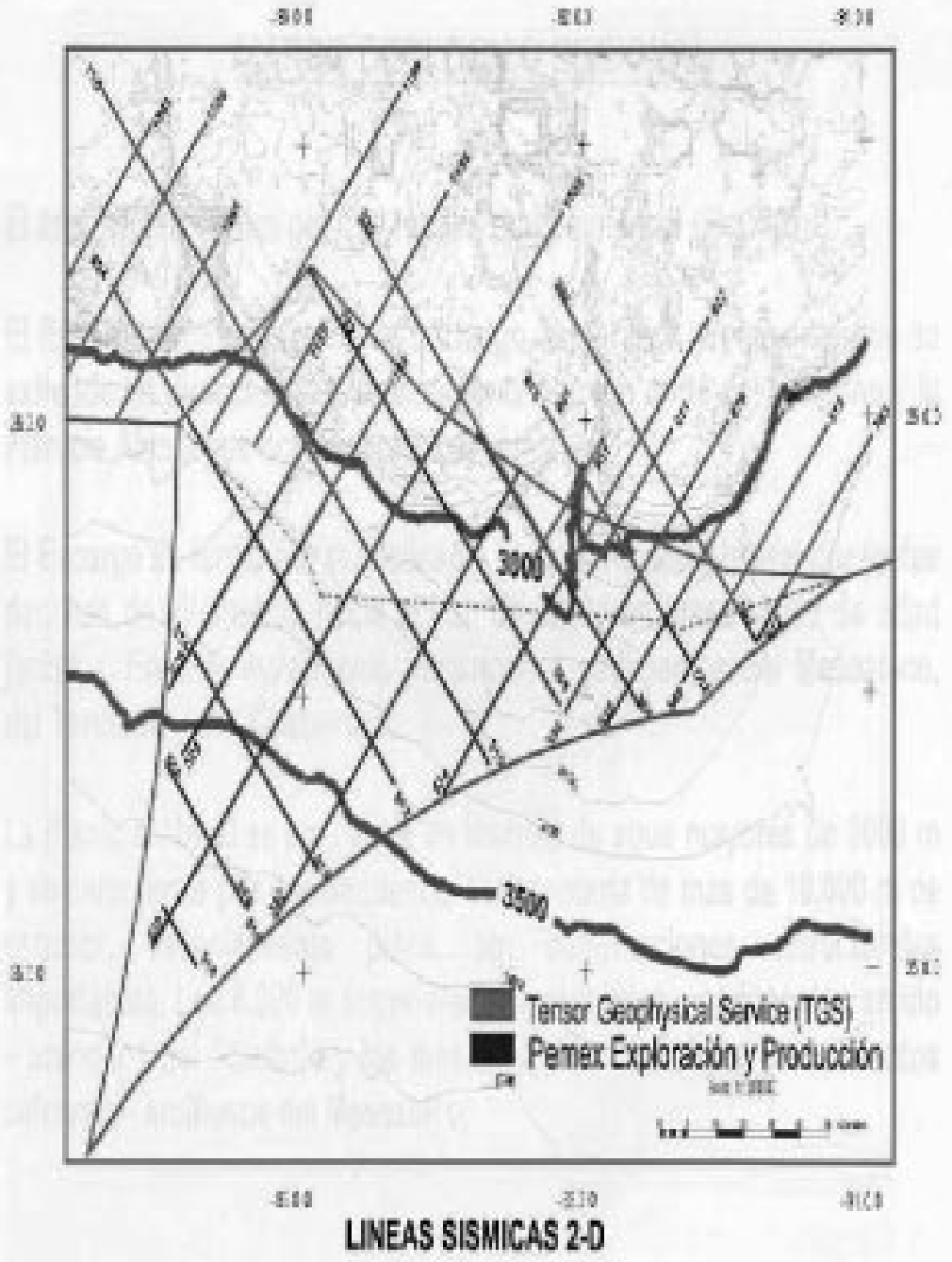

Fig. 5 


\section{MARCO GEOLÓGICO REGIONAL}

El área se caracteriza por dos rasgos predominantes (véase figura 6 en la página siguiente):

- El Escarpe de Sigsbee que es un rasgo fisiográfico prominente que se extiende en dirección esteo-este en la porción norte del polígono y la Planicie Abisal que ocupa el resto del área.

El escarpe se formó por el ascenso y posterior avance lateral por varias decenas de kilómetros hacia el sur, de una gran masa salina de edad jurásica. En este movimiento intrusionó a sedimentos del Mesozoico, del Terciario y del Cuaternario.

- La Planicie Abisal se encuentra en tirantes de agua mayores de 3,000 m y se caracteriza por una secuencia sedimentaria de más de 10,000 $\mathrm{m}$ de espesor, esencialmente plana, sin deformaciones estructurales importantes. Los 6,000 m superiores corresponden a sedimentos arcillo-arenosos del Terciario y los más de 4,000 m inferiores a sedimentos calcáreo-arcillosos del Mesozoico.

\section{COLUMNA GEOLÓGICA}

La columna sedimentaria del área del Polígono Occidental varía en edad del Jurásico al Reciente y la constituyen cinco secuencias sedimentarias que subyacen a un basamento ígneo (véase figura 7 infra p. 97). Esta columna es el resultado de la evolución geológica de la Cuenca del Golfo de México y se caracteriza por sedimentos de aguas profundas.

De acuerdo con la correlación sismo-estratigráfica regional realizada en este estudio, las secuencias sedimentarias corresponden a las unidades conocidas como:

- Challenger, de edad Jurásico Medio-Cretácico Medio, constituida por calizas arcillosas.

- Campeche, de edad Cretácico Superior-Paleoceno, que se subdivide en dos miembros: un miembro inferior de edad Cretácico Superior formado por una secuencia arcillo-calcárea, que marca el final del dominio de la sedimentación carbonatada; y un miembro superior de edad Paleoceno constituido por areniscas y luitas turbidíticas que determinan el inicio del dominio de la sedimentación siliciclástica. 


\section{MARCO GEOLÓGICO REGIONAL}

Lines kso-sos iprotundsade

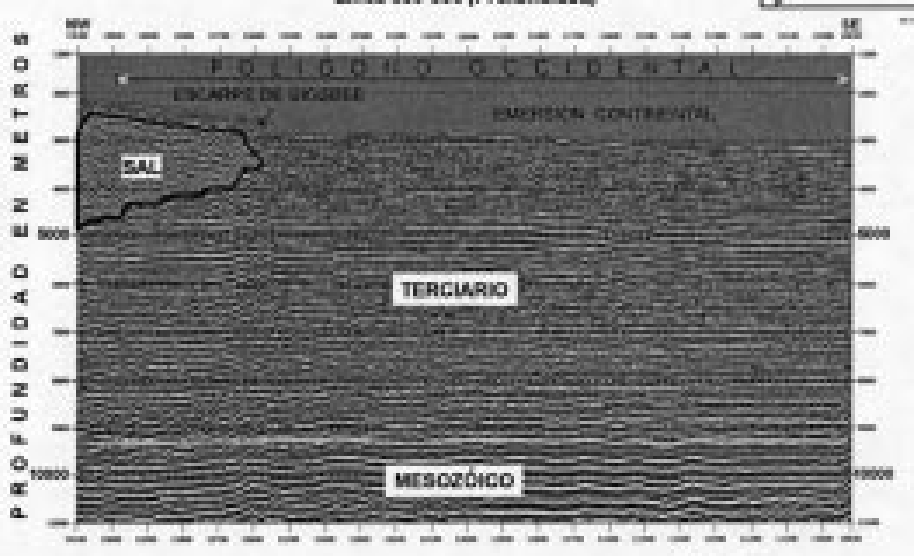

Fig. 6 


\section{COLUMNA GEOLOGICA PROBABLE} POLIGONO OCCIDENTAL
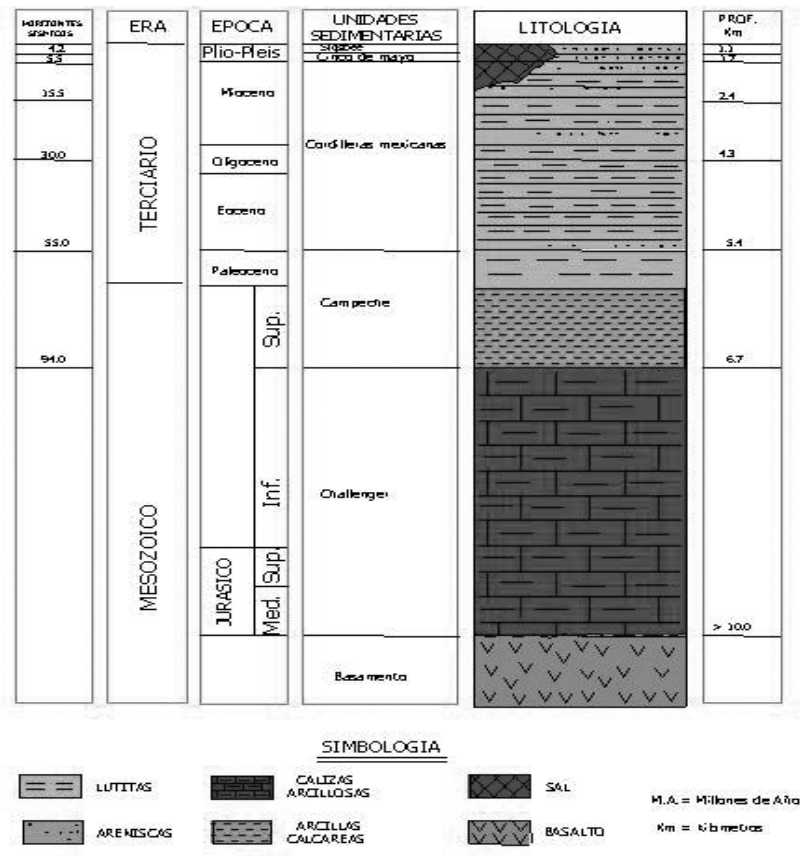

Fig. 7 
- Cordilleras mexicanas de edad Plioceno, formada por lititas y arenas turbidíticas, que en la porción norte del polígono están intrusionadas por masas de sal de edad Jurásico Medio.

- Sigsbee de edad Plioceno Pleistoceno, constituida por secuencias de lititas y arenas turbidíticas, que al igual que Cinco de Mayo, están intrusionadas por masas de sal.

\section{INTERPRETACIÓN}

Con el fin de esclarecer la idea de que por debajo de la masa salina del Escarpe de Sigsbee existen condiciones geológico petroleras diferentes al resto del polígono, que hicieran pensar en la idea de que en esa región existen grandes estructuras capaces de almacenar enormes cantidades de hidrocarburos, se utilizó la sismología como la mayor de las condiciones del subsuelo.

Para la elaboración de este estudio se interpretaron todas las líneas y se seleccionaron para incluirse en este documento las más representativas, que muestran de manera objetiva las características geológicas del área del Polígono Occidental (véase figura 8 en la página siguiente). Estas líneas se presentan en tiempo y en profundidad para comparar el efecto que provoca la presencia de sal en los reflejos debajo de ella.

Asimismo, se incluyen los mapas configurados en profundidad de las unidades Challenger y Cordilleras Mexicanas Superior para mostrar el comportamiento geológico estructural de carácter regional y sus implicaciones petroleras.

\section{LÍNEAS EN TIEMPO}

De manera regional se interpretaron siete horizontes sísmicos que corresponden a los límites de las unidades sedimentarias.

Estos horizontes muestran dos importantes rasgos, uno de ellos es la presencia de reflectores sísmicos relativamente horizontales con buena continuidad asociados a la Planicie Abisal y el otro rasgo importante está relacionado con la presencia de grandes masas salinas cerca del piso marino, bajo las cuales la calidad de la imagen de los reflectores y su posición, se ven fuertemente influenciados tanto por el relieve del piso marino como por los cuerpos salinos en sí. Esta influencia se debe a que la 


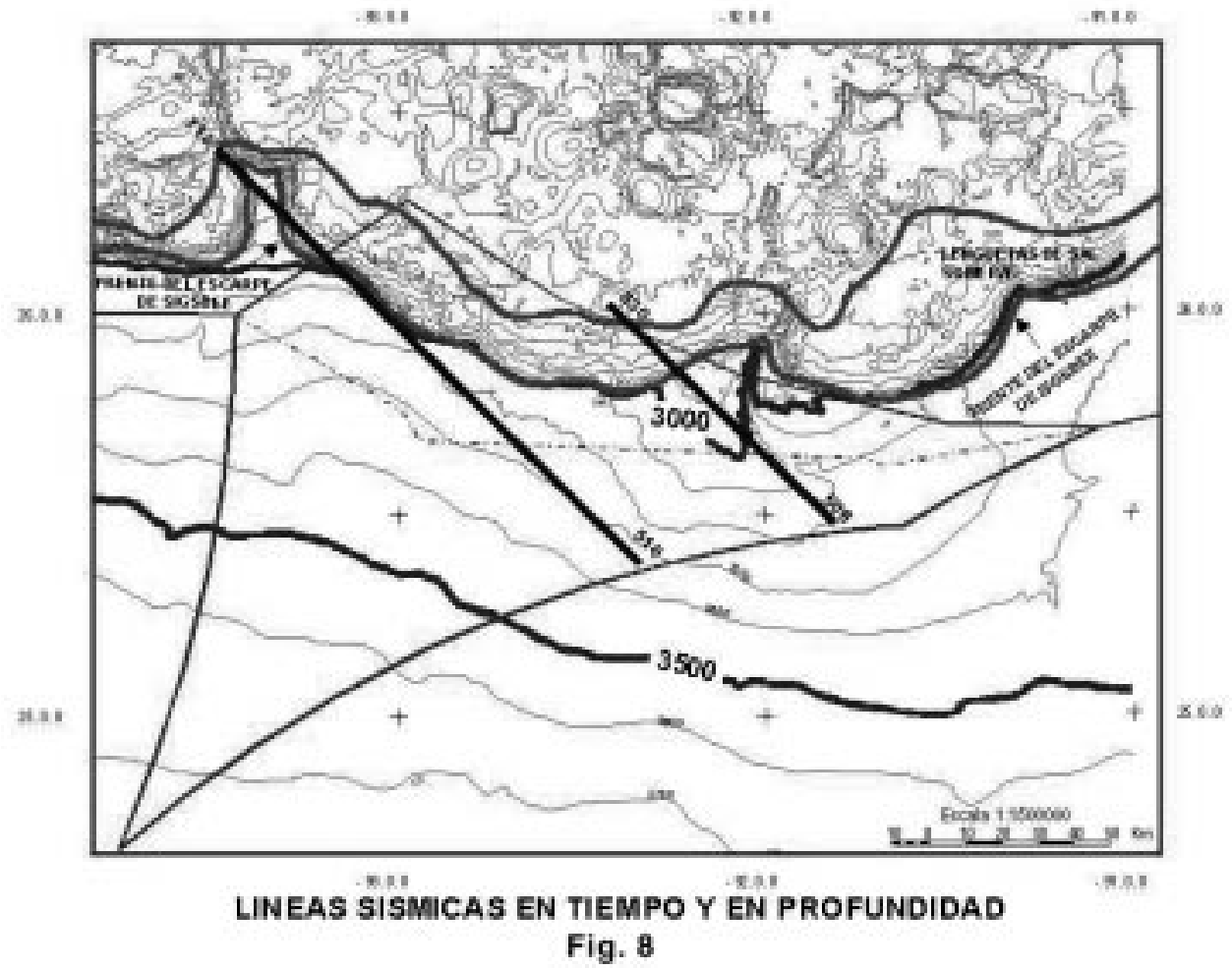


alta velocidad de transmisión de ondas sísmicas en la sal provoca que los reflectores por debajo de ella den la apariencia de que existen estructuras geológicas. Sin embargo, el análisis de las características de los reflectores sísmicos en ambos sectores permitieron identificar y correlacionar dichos eventos.

\section{LÍNEAS EN PROFUNDIDAD}

Con la finalidad de obtener una imagen del subsuelo en la que se eliminen los efectos sísmicos provocados por la presencia de sal y el relieve del piso marino, se procesó la información sísmica para obtener líneas en profundidad. El procesado consistió en eliminar el efecto de la velocidad del cuerpo de sal que tiene entre 1000 y $2000 \mathrm{~m}$ de espesor, lo que provocaba un levantamiento de los reflectores en tiempo. Para ello se utilizaron las velocidades sísmicas que corresponden a cada tipo de roca.

El resultado es la desaparición de las falsas estructuras subsalinas e implica que las condiciones estructurales de las rocas de la Planicie Abisal se extienden por debajo del Escarpe de Sigsbee en la parte norte del Polígono Occidental. Y, por lo tanto, se concluye que toda el área del polígono tiene uniformidad geológica y participa de las características de la Planicie Abisal.

\section{MAPAS DE CONFIGURACIÓN EN PROFUNDIDAD \\ DE LAS UNIDADES CHALLENGER \\ Y CORDILLERAS MEXICANAS}

Los mapas configurados en profundidad se generaron a partir de la interpretación de las líneas sísmicas disponibles en profundidad.

\section{Mapa unidad Challenger}

En este mapa (véase figura 9 en la página siguiente) se aprecia un comportamiento estructural sin deformaciones que muestra una suave tendencia ascendente desde la porción noroeste hacia la parte sureste del área, con una variación de profundidades de 10,000 mbnm a 9,700 mbnm. 


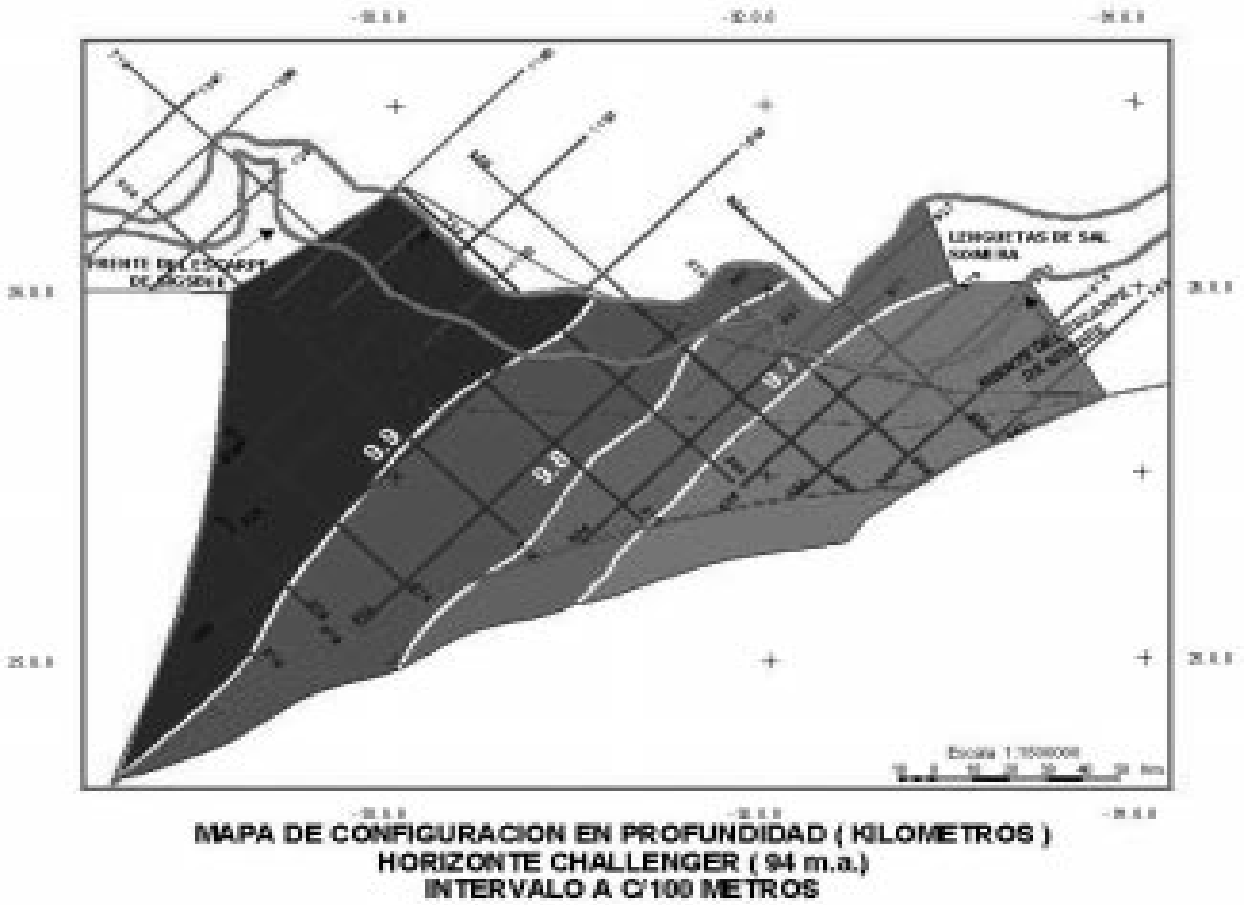

Fig. 9 
Considerando estas profundidades, la ausencia de estructuras, el tirante de agua de mas de 3,000 $\mathrm{m}$ y el probable alto grado de compactación de las rocas arcillo-calcáreas del Mesozoico, éstas resultan de poco interés petrolero.

\section{Mapa unidad Cordilleras Mexicanas Superior}

Aquí, es posible observar que el comportamiento estructural se mantiene relativamente plano, con una suave tendencia descendente que va desde la porción noroeste hacia la porción sureste, con una variación en profundidad desde 3,800 hasta 4,600 m. Tales condiciones implican la ausencia de grandes trampas estructurales capaces de contener hidrocarburos y de que en el caso de existir trampas, éstas serían de tipo estratégico.

\section{GeOlOGÍA PeTROLERA}

En la Cuenca del Golfo de México se ha demostrado que existen cuatro horizontes geológicos generadores de hidrocarburos ubicados en: el Jurásico, el Cretácico, el Eoceno y el Mioceno. Estos cuatro horizontes fueron identificados dentro del área del Polígono Occidental a profundidades que varían entre 4,000 y $8,000 \mathrm{~m}$ bajo el piso marino.

A nivel Terciario, la evolución geológica de la cuenca permite suponer que podrían encontrarse hasta cinco unidades sedimentarias areno-arcillosas con características para constituir rocas almacenadoras de hidrocarburos a profundidades que varían entre 800 y $3500 \mathrm{~m}$ bajo del piso marino.

Estas posibles rocas almacenadoras conformarían probables trampas estratigráficas en donde los posibles sellos serían las rocas arcillosas interestratificadas.

Estructuralmente, el intervalo del Terciario está afectado por fallas normales que podrían dar lugar a pequeñas trampas estratigráficas-estructurales. 


\section{EVALUACIÓN DE LOS RECURSOS PETROLEROS POTENCIALES}

La evaluación de las posibilidades petrolíferas de un área requiere que se analicen y definan los componentes del sistema petrolero, que son:

- Presencia de rocas generadoras de hidrocarburos.

- Presencia de rocas almacenadoras, porosas y permeables.

- Presencia de trampas y rocas sello.

- Migración y sincronía de todos los componentes.

\section{MÉTODO DE BALANCE DE MASAS}

Para la estimación de recursos potenciales petroleros en el Polígono Occidental, se utilizó el método de balance de masas. Este método se basa en la reconstrucción del proceso de transformación de la materia orgánica de hidrocarburos; debido a la evolución térmica de la cuenca, apoyado por el software "BasinMod" para modelado geológico-geoquímico bidimensional de los procesos de generación-migración de hidrocarburos, aplicado a tres líneas sísmicas regionales en profundidad.

Como resultado, se pudo establecer que actualmente el estado térmico de las rocas jurásicas, potencialmente generadoras, es sobremaduro y han agotado su potencial de generación de hidrocarburos. Finalmente, las rocas del Eoceno están en una etapa inicial de madurez sin expulsión, y las del Oligoceno-Mioceno se encuentran inmaduras, tal como se observa en el ejemplo mostrado para el caso de la línea sísmica 830-506 (véase figura 10 en la página siguiente). De acuerdo con lo antes expresado, se postula que son las rocas del Cretácico Superior las que probablemente han generado volúmenes importantes de hidrocarburos en la mayor parte del área, lo que se deduce al observar el mapa de distribución de madurez para este intervalo estratigráfico (véase figura 11 en página posterior a la siguiente).

Utilizando parámetros representativos de las áreas ya conocidas de la Cuenca del Golfo de México, en cuanto al contenido de materia orgánica y su porcentaje de transformación, se ha calculado que el volumen hipotético de hidrocarburos líquidos expulsados en el Polígono Occidental podría ser de 20,226 mmbls y el volumen hipotético de gas expulsado podría ser de $10,067 \mathrm{mmm} 3$. Por lo tanto, la cantidad de hidrocarburos expulsados alcanza un total de 20,300 mmbpce. Sin embargo, la experiencia in- 


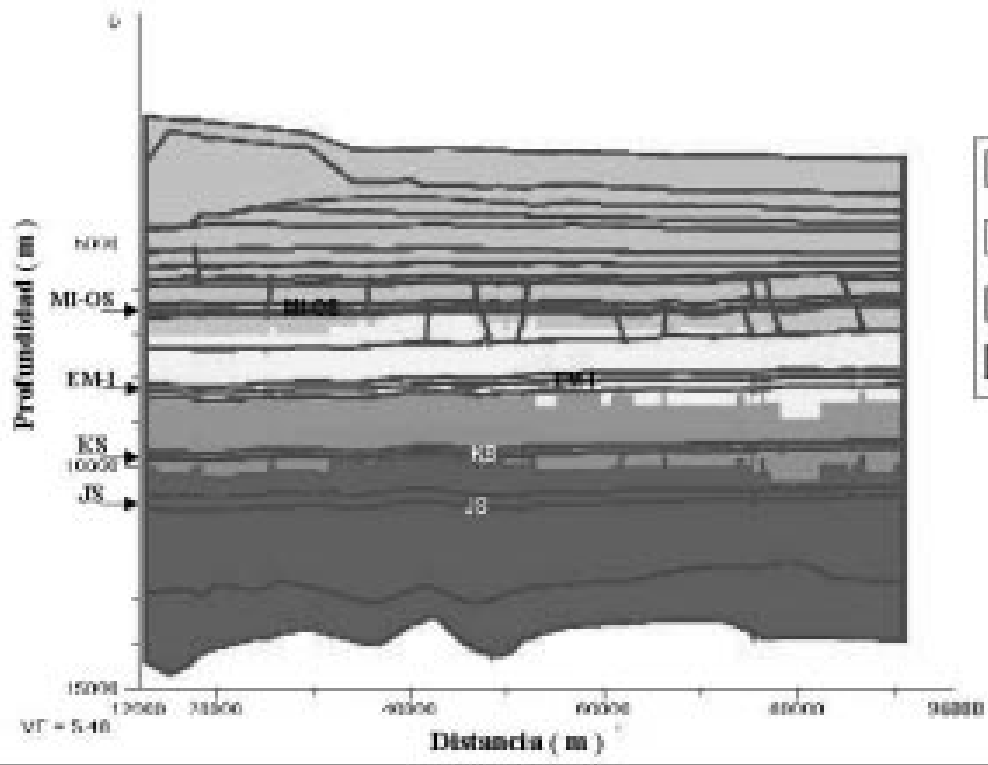

Estado

de

Madurez

DFase hraturs

П Fast tenprom te

getsratiab-ain tzpalaiàt

Fast printipal do

qustratibe

Fast et searsiradurta

MODELO HIPOTETICO DE MADUREZ ACTUAL

LINEA SISMICA $830-506$

Fig. 10

FOCAS GENERADORA

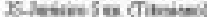

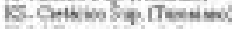

EMH I Eorene Nod - Int

M. Co-Mberso tef-Oter. Iet 


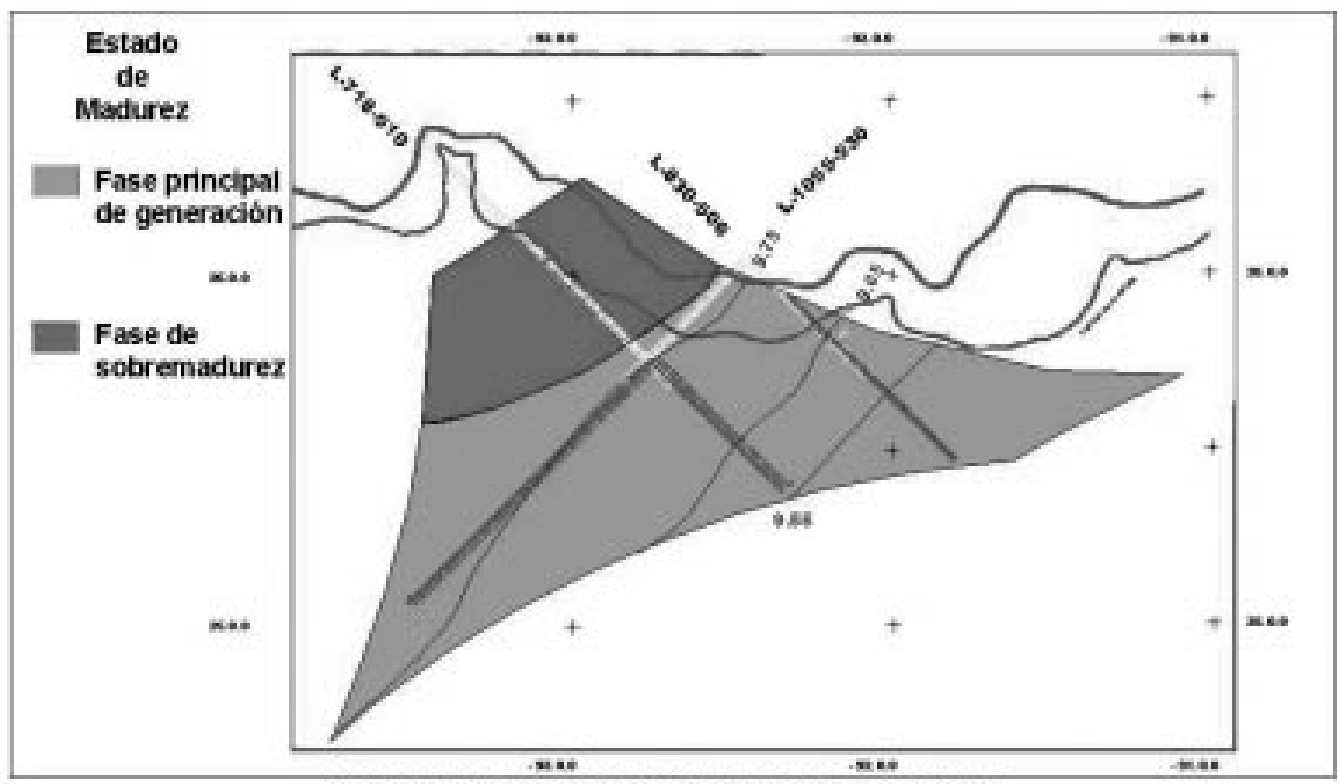

MAPA DE DISTRIBUCION HIPOTETICA DE MADUREZ

ROCA GENERADORA DEL CRETACICO SUPERIOR (TURONIANO)

Fig. 11 
ternacional ha demostrado que la eficiencia de migración máxima, es decir cuando las trampas están inmediatamente arriba de las rocas generadoras activas, no rebasa el $30 \%$. Por lo tanto, en el caso óptimo los recursos potenciales máximos estimados serían 6090 mmbpce.

Por otra parte, en el caso de que las posibles rocas acumuladoras estén alejadas y las vías de migración de hidrocarburos sean escasas, se aplicaría una eficiencia de migración mínima que internacionalmente tiene un valor de 5\%, por lo que el recurso potencial sería del orden de 1015 mmbpce.

Con base en lo señalado anteriormente, se estimó que el volumen medio del recurso potencial es de 2,500 mmbpce.

\section{YACIMIENTOS TRANSFRONTERIZOS}

Debido a la uniformidad geológica que existe en el área del polígono, el volumen estimado podría estar distribuido en yacimientos transfronterizos, como lo ejemplifica el modelo teórico de la figura 12 que se encuentra en la página siguiente.

Los yacimientos transfronterizos son comunes en ciertas partes del mundo, como en el Mar del Norte, donde Noruega comparte campos petroleros con el Reino Unido (véase figura 13 en página posterior a la siguiente).

\section{CONCLUSIONES}

Como resultado de este estudio se pueden postular las siguientes conclusiones:

1. El espesor de la columna sedimentaria que está uniformemente distribuida en el Polígono Occidental es mayor de 10,000 m. Los 6,000 m superiores están constituidos por rocas arcillo-arenosas del Terciario y el resto por rocas calcáreo-arcillosas del Mesozoico.

2. Dentro de la secuencia sedimentaria se postula la existencia de cuatro intervalos de rocas con potencial generador de hidrocarburos y de cinco intervalos con rocas potencialmente acumuladoras.

3. Estructuralmente el área del Polígono Occidental se caracteriza por ser esencialmente plana, no deformada, y por lo tanto sin estructuras geológicas de importancia. Esto incluye el área ubicada por debajo del Escar- 
La uniformitad geologica en el área del poligono occldental podrla dar origen a la existencia de yacimientos transfronterizos. A continuacion se ilustran 2 modelos anälogos.

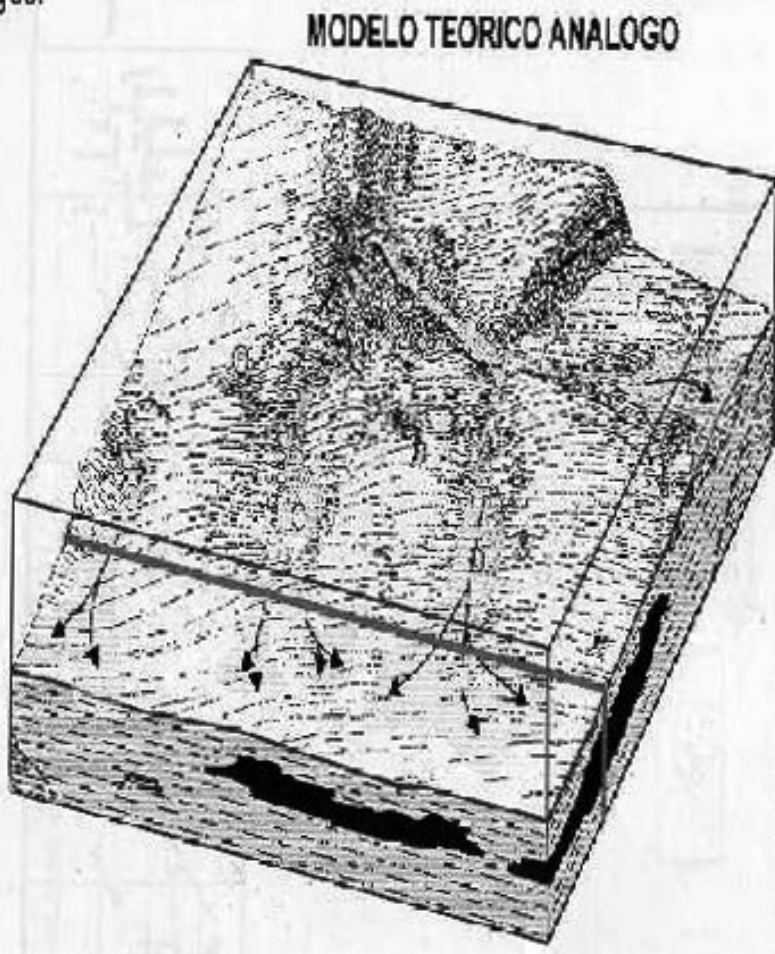

HWERKOWERTCN:IX1

LEYENDR

InIIII RESA

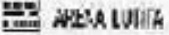

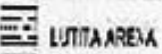

를 LUTih

LOBUOS OE ABANIC:

Cinswes

C.MAS JWEEE condis olstaleutatis

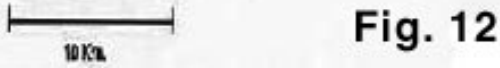

C) NSSVE.06

(9) Mis J:Va: 


\section{EJEMPLOS DE YACIMIENTOS TRANSFRONTERIZOS EN EL MAR DEL NORTE}
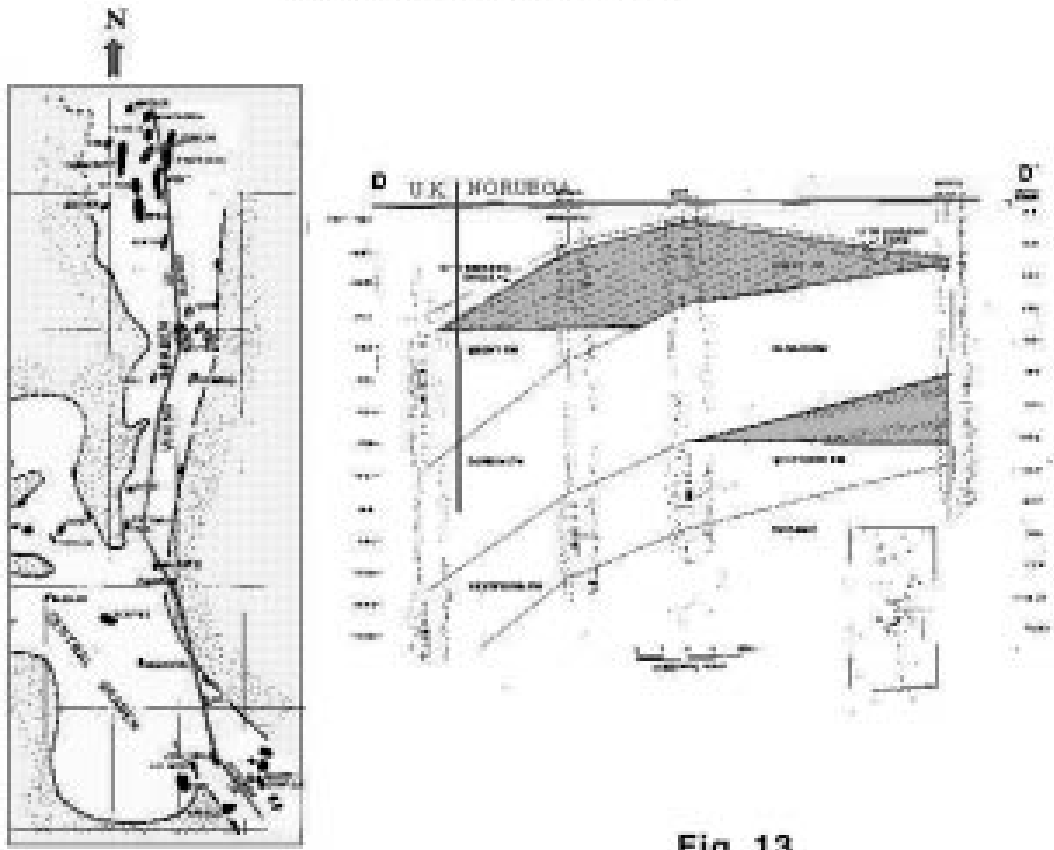

Fig. 13 
pe de Sigsbee, en donde se comprueba la carencia de estructuras que pudieran dar origen a grandes yacimientos de hidrocarburos.

4. Entre los 5000 y $7500 \mathrm{mbnm}$, en toda el área del polígono se observan posibles trampas de pequeñas dimensiones asociadas a fallas normales que pudieran contener hidrocarburos.

5. Los resultados de la estimación de hidrocarburos o cantidad de hidrocarburos disponible para acumularse en el área del Polígono Occidental basada en el método de balance de masas, indican un recurso potencial medio de 2,500 mmbpce.

6. Si se comparan los resultados del potencial petrolero del Polígono Occidental, con respecto a los de otras áreas frontera del Golfo de México, se hace evidente el bajo potencial del Polígono Occidental.

7. Considerando que las características geológico-petroleras son uniformes en toda el área del polígono y que los posibles yacimientos de hidrocarburos serían de tipo estratigráfico, asociados a los patrones de sedimentación del Terciario, es necesario tener en cuenta la muy alta probabilidad de la existencia de yacimientos transfronterizos. 